Article

\title{
Reduction of Photoluminescence Quenching by Deuteration of Ytterbium-Doped Amorphous Carbon-Based Photonic Materials
}

\author{
Hui-Lin Hsu ${ }^{1}$, Keith R. Leong ${ }^{1}$, I-Ju Teng ${ }^{2,3}$, Michael Halamicek ${ }^{1}$, Jenh-Yih Juang ${ }^{2}$, \\ Sheng-Rui Jian ${ }^{3}$, Li Qian ${ }^{1, *}$ and Nazir P. Kherani ${ }^{1,4, *}$
}

1 Department of Electrical and Computer Engineering, University of Toronto,

Toronto, ON M5S 3G4, Canada; E-Mails: huilin.hsu@mail.utoronto.ca (H.-L.H.);

keith.leong@mail.utoronto.ca (K.R.L.); michael.halamicek@mail.utoronto.ca (M.H.)

2 Center for Interdisciplinary Science, National Chiao Tung University, Hsinchu 30010, Taiwan;

E-Mails: eru7023@gmail.com (I-J.T.); jyjuang@nctu.edu.tw (J.-Y.J.)

3 Department of Materials Science and Engineering, I-Shou University, Kaohsiung 84001, Taiwan;

E-Mail: srjian@gmail.com

4 Department of Materials Science and Engineering, University of Toronto, Toronto,

ON M5S 3E4, Canada

* Authors to whom correspondence should be addressed;

E-Mails: 1.qian@utoronto.ca (L.Q.); kherani@ecf.utoronto.ca (N.P.K.);

Tel.: +1-416-946-5517 (L.Q.); +1-416-946-7372 (N.P.K.).

Received: 29 May 2014; in revised form: 21 July 2014 / Accepted: 31 July 2014 /

Published: 6 August 2014

\begin{abstract}
In situ $\mathrm{Yb}$-doped amorphous carbon thin films were grown on Si substrates at low temperatures $\left(<200{ }^{\circ} \mathrm{C}\right)$ by a simple one-step RF-PEMOCVD system as a potential photonic material for direct integration with Si CMOS back end-of-line processing. Room temperature photoluminescence around $1 \mu \mathrm{m}$ was observed via direct incorporation of optically active $\mathrm{Yb}^{3+}$ ions from the selected $\mathrm{Yb}$ (fod $)_{3}$ metal-organic compound. The partially fluorinated $\mathrm{Yb}(\mathrm{fod})_{3}$ compound assists the suppression of photoluminescence quenching by substitution of $\mathrm{C}-\mathrm{H}$ with $\mathrm{C}-\mathrm{F}$ bonds. A four-fold enhancement of $\mathrm{Yb}$ photoluminescence was demonstrated via deuteration of the a-C host. The substrate temperature greatly influences the relative deposition rate of the plasma dissociated metal-organic species, and hence the concentration of the various elements. $\mathrm{Yb}$ and $\mathrm{F}$ incorporation are promoted at lower substrate temperatures, and suppressed at higher substrate temperatures. $\mathrm{O}$ concentration is slightly elevated at higher substrate temperatures.
\end{abstract}


Photoluminescence was limited by the concentration of $\mathrm{Yb}$ within the film, the concentration of $\mathrm{Yb}$ ions in the +3 state, and the relative amount of quenching due to the various de-excitation pathways associated with the vibrational modes of the host a-C network. The observed wide full-width-at-half-maximum photoluminescence signal is a result of the variety of local bonding environments due to the a-C matrix, and the bonding of the $\mathrm{Yb}^{3+}$ ions to $\mathrm{O}$ and/or $\mathrm{F}$ ions as observed in the $\mathrm{X}$-ray photoelectron spectroscopy analyses.

Keywords: RF-PEMOCVD; fluorinated ytterbium metal-organic compound; deuterated; hydrogenated; amorphous carbon

\section{Introduction}

The integration of optical technologies into microelectronic devices has been researched as a viable solution to overcome the speed bottlenecks associated with the ever shrinking of device feature size [1]. Er-implanted in $\mathrm{Si}, \mathrm{SiO}_{2}$, and ceramic based host thin films [2,3] has been shown to produce photons efficiently from $\mathrm{Er}^{3+}$ ions at $1.5 \mu \mathrm{m}$, a strategic wavelength for telecommunications. Nevertheless, the ideal optical wavelength for applications on a Si chip and in chip-to-chip communications has not been determined. In order to make use of optical technologies fully, it is essential to explore each alternative $\mathrm{Si}$ compatible photonic material. Further, the synthesis techniques of these materials need to be compatible with current Si integrated circuit (IC) fabrication technology. Moreover, it is desirable to develop material growth processes at temperatures below $400{ }^{\circ} \mathrm{C}$ in order to meet the Si back end-of-line (BEOL) requirements [4].

Ytterbium ( $\mathrm{Yb}$ ) doped yttrium-aluminum garnet $\mathrm{Y}_{3} \mathrm{Al}_{5} \mathrm{O}_{12}$ (YAG) single crystals have appeared as promising competitors to the traditional neodymium $(\mathrm{Nd})$ based solid laser for high power diode pumped waveguides [5] and thin-disk lasers [6]. Yb exhibits a simple electronic structure with two manifold levels, a ${ }^{2} \mathrm{~F}_{7 / 2}$ ground state and a ${ }^{2} \mathrm{~F}_{5 / 2}$ excited state. It has been demonstrated that Yb:YAG lasers lack excited-state absorption, or up-conversion effect owing to a cross-relaxation between the active $\mathrm{Yb}^{3+}$ ions [7]. Also, $\mathrm{Yb}$ doping concentration can be high due to the enhanced probability of $\mathrm{Yb}^{3+}$ substitution of $\mathrm{Y}^{3+}$ ions in YAG single crystals [8]. Moreover, $\mathrm{Yb}$ has a long luminescence lifetime [9] (up to $1 \mathrm{~ms}$ ), and a relatively large emission cross section which results in a higher pumping efficiency [10] compared to $\mathrm{Nd}$ based solid lasers. However, Yb:YAG single crystals grown via the Czochralski technique possess an inhomogeneous distribution of the active impurities. In particular, the Czochralski technique is not suitable for the fabrication of planar thin film optoelectronic devices integrated on a Si chip platform without convoluted multi-wafer bonding schemes.

Incorporation of $\mathrm{Yb}$ into ceramic-based (YAG [11-13], $\mathrm{Y}_{2} \mathrm{SiO}_{5}$ (YSO) [14-16], $\mathrm{KY}\left(\mathrm{WO}_{4}\right)_{2}$ [17], $\mathrm{NaLu}\left(\mathrm{WO}_{4}\right)_{2}$ [18], and $\mathrm{Al}_{2} \mathrm{O}_{3}$ [19,20]) wide bandgap semiconductors, oxide-based semiconductors ( $\mathrm{ZnO}$ [21-23], $\mathrm{TiO}_{2}$ [24,25], $\mathrm{In}_{2} \mathrm{O}_{3}$ [26]), III-V group based materials (AlN [27]), and Si-based [28] thin film hosts using various deposition techniques, have been shown to produce luminescence at a wavelength of around $1 \mu \mathrm{m}$. For Yb doped YAG [11], YSO [14,15], and $\mathrm{KY}\left(\mathrm{WO}_{4}\right)_{2}$ [17] thin films, the liquid phase epitaxial (LPE) method has been employed to fabricate homogeneous crystalline films from a molten solute diluted in a solvent. Their growth and post-deposition annealing temperatures are as 
high as $900-1300{ }^{\circ} \mathrm{C}$ so as to avoid growth defects and to further improve the film quality $[11,14,15]$. In addition, a flat oriented YAG and/or YSO single crystalline substrate is needed as a seed in the LPE method, since growth of the single crystal film is performed by dipping the substrate in a supersaturated melt solution [29]. Consequently, the LPE processing method is not compatible with current Si-based IC fabrication technology.

Lower substrate temperature growth $\left(<300{ }^{\circ} \mathrm{C}\right)$ of amorphous or poly-crystalline/crystalline Yb-doped films (i.e., YAG [13], $\mathrm{Y}_{2} \mathrm{O}_{3}$ [30], $\mathrm{Al}_{2} \mathrm{O}_{3}$ [19,20], $\mathrm{CoSb}_{3}$ [31], $\mathrm{ZnO}$ [23], ITO [32], AlN [27], and Si-based [28] hosts) and crystalline $\mathrm{Yb}_{2} \mathrm{O}_{3}$ film [33] on Si-based and/or sapphire substrates was achieved via pulsed laser ablation (PLD) [13,19,20,28,30,31,33] and magnetron sputtering [23,27,32] of $\mathrm{Yb}$ containing targets. While it is highly desirable to directly employ $\mathrm{Si}$ as the host in optoelectronic devices, the bulk crystalline Si bandgap energy is not large enough to activate $\mathrm{Yb}$ luminescence. Thus, nanocrystalline silicon (nc-Si) hosts have been applied to act as an efficient sensitizer to transfer photo-induced carriers from the host to the $\mathrm{Yb}^{3+}$ ions. Photoluminescence (PL) has been obtained at temperatures ranging from approximately $20-300 \mathrm{~K}$ in $\mathrm{Yb}$ doped nc-Si films fabricated by ablating a Si: $\mathrm{Yb}_{2} \mathrm{O}_{3}$ mixture target [28]. Moreover, co-doping with $\mathrm{O}_{2}$ was highly preferred during the ablation to enhance PL efficiency. Enhancement was achieved through the formation of $\mathrm{Yb}-\mathrm{O}$ bonds and the reduction in $\mathrm{Yb}$ segregation. For PLD grown $\mathrm{Yb}_{2} \mathrm{O}_{3}$ films, room temperature $\mathrm{PL}$ was not observed [33]. This was attributed to high $\mathrm{Yb}$ concentrations, leading to fast energy migration from one $\mathrm{Yb}$ site to another and non-radiative de-excitation. Despite the achievement of lower growth temperatures, the concentration of the $\mathrm{Yb}$ and the properties of the host material cannot be independently controlled with pulsed laser ablation and magnetron sputtering techniques. Also, multiple targets with varying $\mathrm{Yb}$ composition would be required to obtain different concentrations of Yb-doped films. In addition, a high temperature $\left(>600{ }^{\circ} \mathrm{C}\right)$ post-deposition annealing step is always required to promote the formation of optically active $\mathrm{Yb}^{3+}$ ions and to enhance the PL efficiency. This post-deposition annealing step is not amenable with current Si BEOL fabrication technology.

Although extensive research has been performed on $\mathrm{Yb}$-doped ceramic and oxide thin films deposited via various methods, $\mathrm{Yb}$ doping in carbon based hosts has been minimal. $\mathrm{Yb}$ nanocrystals have been incorporated in various polymers as hybrid materials using sol-gel for potential bio imaging [34,35], gas adsorption, and catalytic activity [36] applications. Hydrogenated amorphous carbon has been used as a host for Er and Yb, however, the attempted PL enhancement of Er via Yb sensitization was not achieved for samples prepared by sputtering of a hybrid Er/Yb/carbon target [37]. An alternative approach for the growth of hydrogenated amorphous carbon $(\mathrm{a}-\mathrm{C}: \mathrm{H})$ films is by Plasma Enhanced Chemical Vapor Deposition (PECVD) methods, an approach which is compatible with current CMOS fabrication technology [38]. This methodology facilitates integration and allows for reproducible and low-cost films. Additionally, a-C based films possess a number of outstanding properties such as high chemical resistance, mechanical hardness, and transparency in the infrared $[38,39]$. The specific properties of a-C:H films can be tailored over a wide range by adjusting the amount of $s p^{3}$ and $s p^{2}$ hybridized carbon and the incorporated hydrogen content in the film via various deposition parameters and methods [39]. These unique and versatile properties provide an impetus to utilize PECVD a-C:H films for specific optoelectronic applications. More importantly, it has been demonstrated that it is possible to prepare carbon based planar waveguides with an attenuation of less than $1 \mathrm{~dB} / \mathrm{cm}$ [40]. 
Having low optical losses in photonic materials is one of the most important prerequisites for employing a given material in integrated optics.

In this work, $\mathrm{Yb}$-doped $\mathrm{a}-\mathrm{C}$ based thin films $(\mathrm{a}-\mathrm{C}(\mathrm{Yb}))$ were prepared by simple occlusion of the metal-organic compound at low temperatures $\left(<200{ }^{\circ} \mathrm{C}\right)$ in a radio frequency plasma enhanced metal-organic chemical vapor deposition (RF-PEMOCVD) system. The enhancement of PL by substitution of $\mathrm{O}-\mathrm{H}$ and $\mathrm{C}-\mathrm{H}_{\mathrm{x}}$ bonds with $\mathrm{O}-\mathrm{D}$ and $\mathrm{C}-\mathrm{D}_{\mathrm{x}}$ bonds is probed and discussed in detail. The effect of the substrate temperature on the PL of a-C(Yb) films is investigated and correlated to the film microstructure and bonding environment. The change in the optical properties of the host a-C upon incorporation of fluorinated $\mathrm{Yb}$ metal-organic compound is also discussed.

\section{Results and Discussion}

\subsection{Photoluminescence Enhancement in $a-C(Y b)$ Film by Deuteration of a-C Host}

The bonding environment of the $\mathrm{Yb}$ ions in the selected $\mathrm{Yb}$ metal-organic compound tris(6,6,7,7,8,8,8-heptafluoro-2,2-dimethyl-3,5-octanedionate) Ytterbium (+III), abbreviated $\left(\mathrm{Yb}(\mathrm{fod})_{3}\right)$, having the chemical structure $\mathrm{Yb}\left(\mathrm{C}_{10} \mathrm{H}_{10} \mathrm{~F}_{7} \mathrm{O}_{2}\right)_{3}$, is similar to that in $\mathrm{Yb}_{2} \mathrm{O}_{3}$. These optically active $\mathrm{Yb}^{3+}$ ions can be preserved under appropriate plasma deposition conditions without the need of a post-deposition annealing step. Fluorine is also incorporated via the partially fluorinated $\mathrm{Yb}(\mathrm{fod})_{3}$ precursor. The effect of fluorine on the structure and properties of the films is discussed in Section 2.4. It is noteworthy that the resultant a-C:H:F(Yb) films may contain $\mathrm{O}-\mathrm{H}$ bonds which form during the decomposition of the $\mathrm{Yb}$ (fod $)_{3}$ vapor flux which mixes with the methane $\left(\mathrm{CH}_{4}\right)$ plasma. Although the source of oxygen is limited in the $\mathrm{Yb}(\mathrm{fod})_{3}$ precursor, the residual coordinated solvent molecules in the $\mathrm{Yb}(\mathrm{fod})_{3}$ compound may also contribute to the overall source of oxygen and hydrogen. In addition, the a-C:H:F(Yb) films will contain $\mathrm{C}-\mathrm{H}$ bonds where the source of hydrogen includes the methane precursor gas and the existing ligands from $\mathrm{Yb}(\text { fod })_{3}$ vapor. Hence, prior to a-C:H:F(Yb) film formation via the RF-PEMOCVD method, the impact of the neighboring $\mathrm{C}-\mathrm{H}_{\mathrm{x}}$ and $\mathrm{O}-\mathrm{H}$ bonds in the host on the PL of the selected $\mathrm{Yb}$ (fod $)_{3}$ precursor was investigated. The $0.5 \mathrm{mM} \mathrm{Yb}(\mathrm{fod})_{3}$ powder was dissolved in chloroform $\left(\mathrm{CHCl}_{3}\right)$, methanol $\left(\mathrm{CH}_{3} \mathrm{OH}\right)$, and their respective deuterated solvents, i.e., chloroform-d $\left(\mathrm{CDCl}_{3}\right)$ and methanol- $\mathrm{d}_{4}\left(\mathrm{CD}_{3} \mathrm{OD}\right)$. It can be seen in Figure 1a that the PL intensity is enhanced by a factor of 2.4 as the solvent $\mathrm{CHCl}_{3}$ is replaced with $\mathrm{CDCl}_{3}$. This suggests the $\mathrm{Yb}(\mathrm{fod})_{3} \mathrm{PL}$ is quenched by the $\mathrm{C}-\mathrm{H}$ bonds in neighboring solvent molecules. Figure $1 \mathrm{~b}$ displays the PL enhancement by a factor of five when using the $\mathrm{CD}_{3} \mathrm{OD}$ solvent instead of the $\mathrm{CH}_{3} \mathrm{OH}$ solvent. Since the $\mathrm{CH}_{3} \mathrm{OH}$ host solvent molecules contain both $\mathrm{C}-\mathrm{H}_{\mathrm{x}}$ and $\mathrm{O}-\mathrm{H}$ bonds, the $\mathrm{PL}$ quenching of $\mathrm{Yb}(\text { fod })_{3}$ is more significant. As previously shown, $\mathrm{O}-\mathrm{H}$ bonds contribute non-radiative deactivation channels for excited $\mathrm{Yb}^{3+}$ ions [41-43]. It has been demonstrated that the $\mathrm{Yb}$ radiative lifetime is limited by the presence of $\mathrm{O}-\mathrm{H}$ groups in the sol-gel silica glass host matrix [42]. Hence, hydrogen containing groups such as $\mathrm{X}-\mathrm{H}$ (where $\mathrm{X}=\mathrm{O}, \mathrm{C}$ ) appear to aid in PL quenching due to the proximity of their vibrational modes to the excited states of $\mathrm{Yb}$ ions as indicated in Figure 2. To suppress the $\mathrm{O}-\mathrm{H}$ and $\mathrm{C}-\mathrm{H}_{\mathrm{x}}$ quenching effect near the $\mathrm{Yb}^{3+}$ ions in $\mathrm{a}-\mathrm{C}: \mathrm{H}: \mathrm{F}(\mathrm{Yb})$ films, the precursor gas was changed from methane $\left(\mathrm{CH}_{4}\right)$ to deuterated methane $\left(\mathrm{CD}_{4}\right)$. This reduces the formation of $\mathrm{O}-\mathrm{H}$ and $\mathrm{C}-\mathrm{H}_{\mathrm{x}}$ bonds which are now substituted by $\mathrm{O}-\mathrm{D}$ and $\mathrm{C}-\mathrm{D}_{\mathrm{x}}$ bonds $[44,45]$. 
Figure 1. Comparison of the Photoluminescence (PL) intensity of $\mathrm{Yb}(\mathrm{fod})_{3}$ powder dissolved in (a) chloroform $\left(\mathrm{CHCl}_{3}\right)$ and chloroform-d $\left(\mathrm{CDCl}_{3}\right)$; in $(\mathbf{b})$ methanol $\left(\mathrm{CH}_{3} \mathrm{OH}\right)$ and methanol- $\mathrm{d}_{4}\left(\mathrm{CD}_{3} \mathrm{OD}\right)$; (c) Comparison of the PL intensity of a-C:D:F(Yb: 1.6 at \% ) and a-C:H:F(Yb: 1.6 at \%) films prepared using $\mathrm{RF}$ power of $60 \mathrm{~W}$, precursor gas flow rate of $20 \mathrm{sccm}$, deposition pressure of 60 mTorr, substrate temperature of $90{ }^{\circ} \mathrm{C}$, and $\mathrm{Yb}(\mathrm{fod})_{3}$ powder evaporation temperature of $110^{\circ} \mathrm{C}$.

(a)

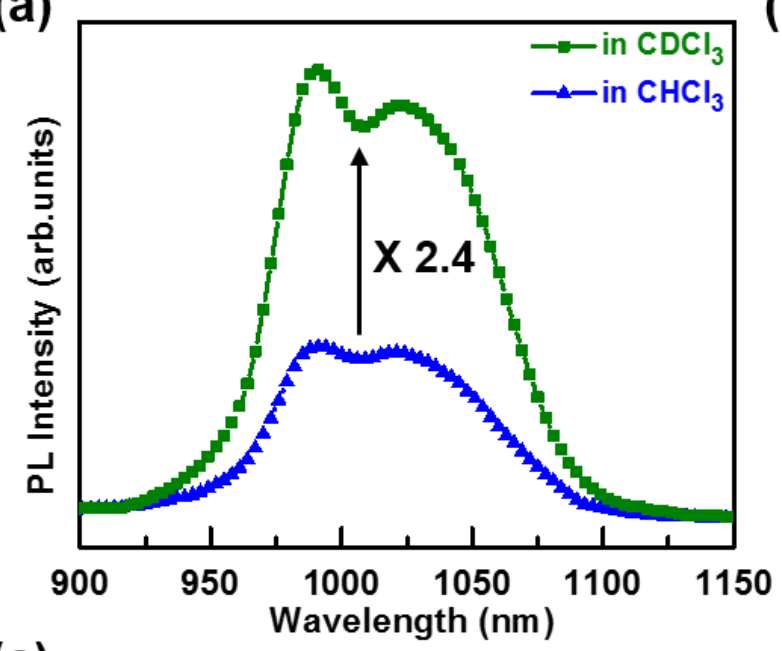

(b)

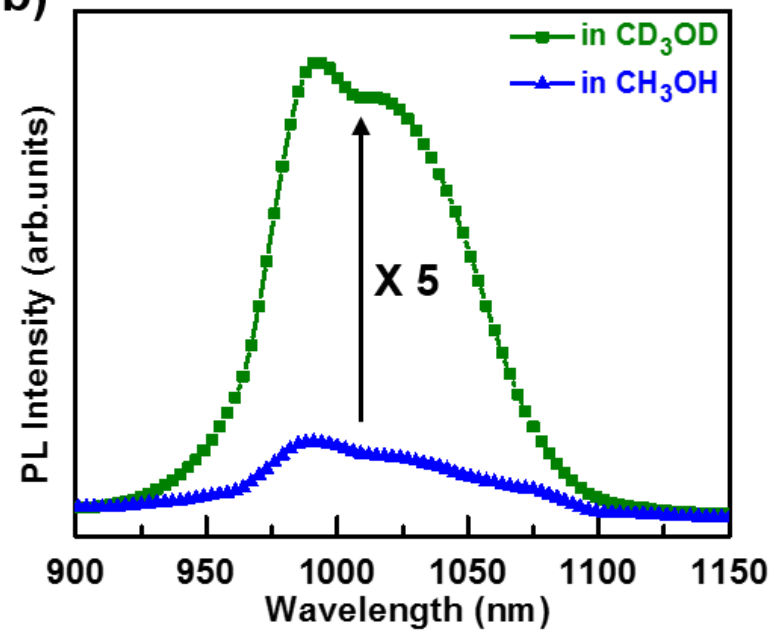

(c)

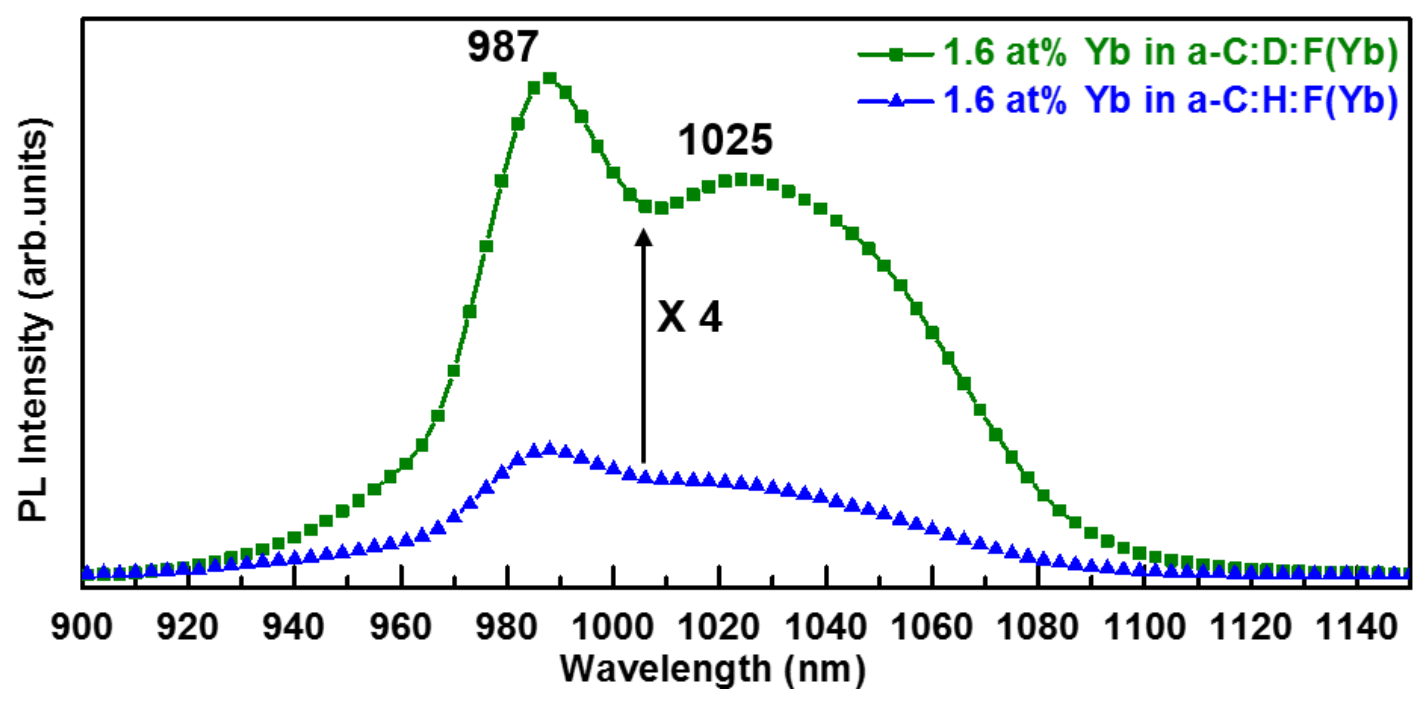

The room temperature PL spectra of a-C(Yb) samples exhibit peaks around 987 and $1025 \mathrm{~nm}$, shown in Figure 1c, which corresponds to the ${ }^{2} F_{5 / 2}$ to ${ }^{2} F_{7 / 2}$ electronic transition of $\mathrm{Yb}^{3+}$ ions in Figure 2. The spectral width of the emission band is attributed to inhomogeneous and homogeneous broadening in addition to Stark splitting of the $\mathrm{Yb}^{3+}$ excited and ground states. Its full width at half-maximum (FWHM) is approximately $85 \mathrm{~nm}$, suggesting the potential of enabling a wide gain bandwidth for optical amplification and tunable laser design. However, the FWHM of $\sim 85 \mathrm{~nm}$ in the a-C(Yb) samples is slightly smaller than that obtained from the $\mathrm{Yb}(\mathrm{fod})_{3}$ containing solutions shown in Figures 1a,b ( $90 \mathrm{~nm})$. This suggests the $\mathrm{Yb}^{3+}$ state is relatively preserved compared to that of the pristine $\mathrm{Yb}(\mathrm{fod})_{3}$ compound in solution, a highly disordered local environment. In addition, the PL peak of the $\mathrm{a}-\mathrm{C}(\mathrm{Yb})$ samples is wider than those of other $\mathrm{Yb}$ doped ceramic and oxide based hosts $[13,25,46,47]$. This suggests the $\mathrm{Yb}^{3+}$ ion possesses a variety of local bonding environments in 
the a-C matrix, which will be discussed further in the X-ray photoelectron spectroscopy (XPS) analyses in Section 2.4. Figure 1c shows the PL intensity is enhanced by a factor of four for the same $\mathrm{Yb}$ concentration in the deuterated a-C matrix as opposed to the hydrogenated a- $\mathrm{C}$ matrix. This confirms that $\mathrm{Yb}$ photoluminescence is enhanced through the substitution of $\mathrm{O}-\mathrm{H}$ and $\mathrm{C}-\mathrm{H}_{\mathrm{x}}$ groups with $\mathrm{O}-\mathrm{D}$ and $\mathrm{C}-\mathrm{D}_{\mathrm{x}}$ groups in the $\mathrm{a}-\mathrm{C}(\mathrm{Yb})$ films prepared by the RF-PEMOCVD method. Nevertheless, the enhanced luminescence factor for the deuterated a-C(Yb) sample is lower than that of the $\mathrm{Yb}(\mathrm{fod})_{3}$ deuterated methanol solution as shown in Figure 1b. The factors that may contribute to the lower PL enhancement for the deuterated $\mathrm{a}-\mathrm{C}(\mathrm{Yb})$ sample include the presence of $\mathrm{C}-\mathrm{H}_{\mathrm{x}}$ bonds within the host that may reside in close proximity to the $\mathrm{Yb}^{3+}$ ions for the given deposition conditions and/or some of the $\mathrm{Yb}$ ions in $\mathrm{a}-\mathrm{C}(\mathrm{Yb})$ not being in the optically active $3+$ state which is discussed in Section 2.2 and presented in Table 1.

Figure 2. Illustration of energy levels of the vibrational modes for $\mathrm{O}-\mathrm{H}, \mathrm{O}-\mathrm{D}, \mathrm{C}-\mathrm{H}_{\mathrm{x}}$, and $\mathrm{C}-\mathrm{D}_{\mathrm{x}}$ bonds in the solid state, where the range of each vibrational mode is inferred from Fourier transform infrared spectroscopy (FTIR) spectra of the host a-C:H, a-C:D and fluorinated a-C:D films (a-C:D:F) as displayed in Figure 3. The grey band here is used to represent the highly varying bonding structure, which reflects the levels associated with the numerous combinations of nearest neighbors and the different local bonding environments.

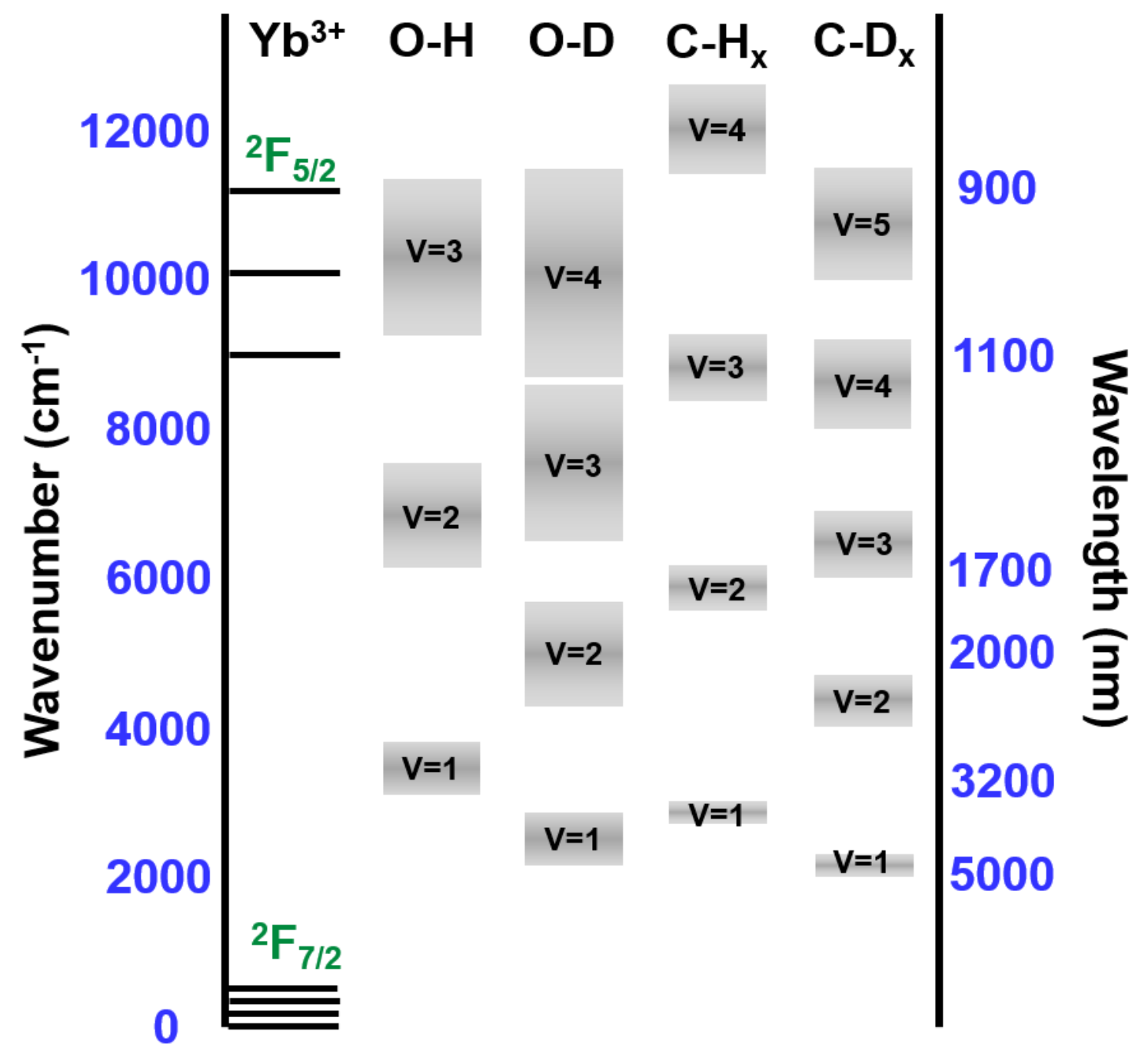


Table 1. Ratios of atomic concentrations and relative/absolute atomic concentrations of relevant elements in as-received stoichiometric $\mathrm{Yb}(\mathrm{fod})_{3}$ compound, and in six a-C:D:F(Yb) films deposited under varying conditions as determined from XPS measurements.

\begin{tabular}{|c|c|c|c|c|c|c|c|c|c|c|c|c|}
\hline Sample & Substrate temperature $\left({ }^{\circ} \mathrm{C}\right)$ & C at \% & $\mathrm{O}$ at $\%$ & F at $\%$ & Yb at $\%$ & $\%[\mathbf{O}] /[\mathbf{Y b}]$ & {$[\mathbf{F}] /[\mathbf{Y b}]$} & {$[\mathbf{C}] /[\mathbf{Y b}]$} & {$[\mathrm{O}] /[\mathrm{C}]$} & {$[\mathbf{F}] /[\mathbf{C}]$} & {$[\mathbf{O}] /[\mathrm{F}]$} & Thickness $(100 \mathrm{~nm})$ \\
\hline $\mathrm{Yb}(\text { fod })_{3}$ & & 34.1 & 6.8 & 23.9 & 1.1 & 6.00 & 21.00 & 30.00 & 0.20 & 0.70 & 0.29 & \\
\hline 1 & 60 & 48.5 & 2.7 & 45.2 & 3.6 & 0.75 & 12.72 & 13.64 & 0.06 & 0.93 & 0.06 & 33.21 \\
\hline 2 & 70 & 59.9 & 2.5 & 35.0 & 2.6 & 0.94 & 13.23 & 22.64 & 0.04 & 0.58 & 0.07 & 27.65 \\
\hline 4 & 90 & 68.9 & 3.2 & 26.3 & 1.6 & 1.99 & 16.25 & 42.63 & 0.05 & 0.38 & 0.12 & 14.52 \\
\hline 5 & 120 & 86.4 & 7.2 & 5.5 & 0.9 & 8.00 & 6.05 & 95.73 & 0.08 & 0.06 & 1.32 & 5.67 \\
\hline 6 & 150 & 91.8 & 6.1 & 1.7 & 0.4 & 17.50 & 4.84 & 261.64 & 0.07 & 0.02 & 3.62 & 3.51 \\
\hline
\end{tabular}


Figure 3. FTIR spectra of the host a-C:H, a-C:D, and a-C:D:F $\left(\mathrm{CF}_{4} /\left[\mathrm{CF}_{4}+\mathrm{CD}_{4}\right]=50\right.$ vol.\%) films without $\mathrm{Yb}$ metal-organic compound incorporation prepared under the same deposition condition except for the precursor gas. The relative wavenumber/wavelength positions and the range of the first vibrational mode illustrated in Figure 2 are inferred from this data.

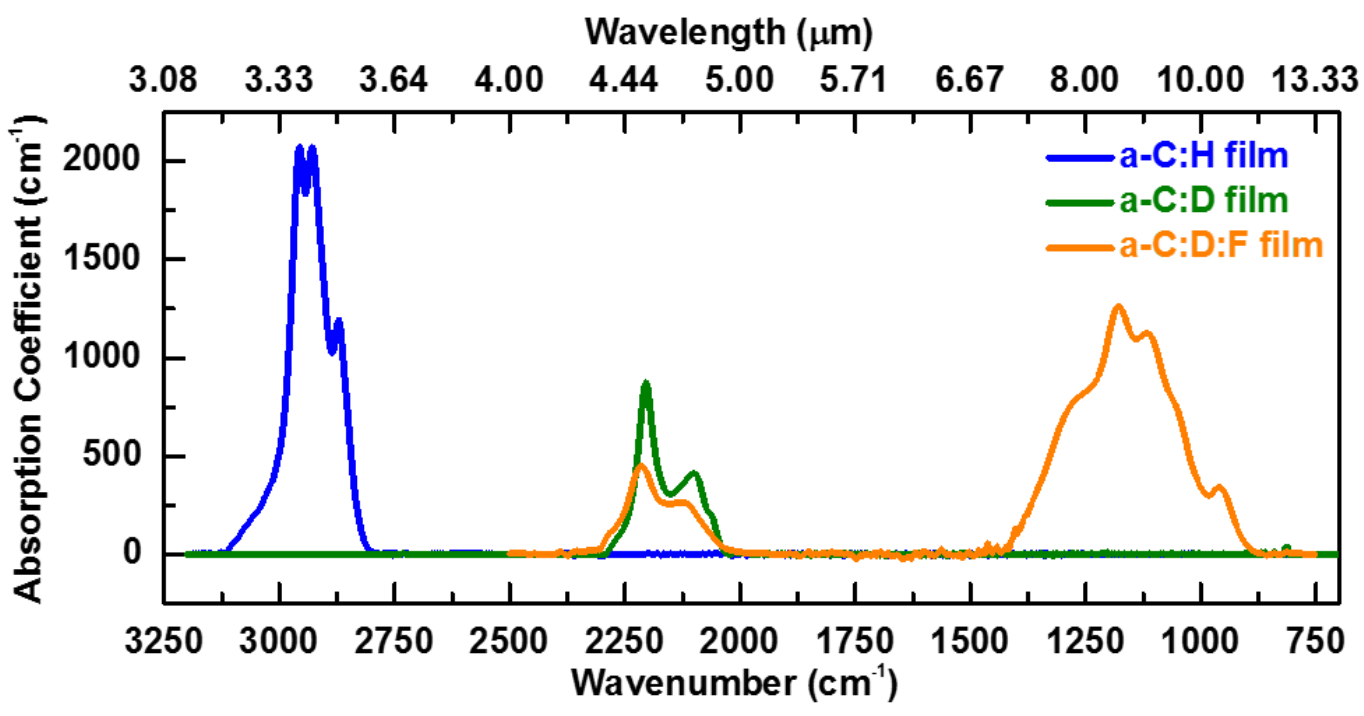

The enhancement of PL is primarily attributed to the weaker interaction strength between $\mathrm{Yb}^{3+}$ and the $\mathrm{O}-\mathrm{D}$ fourth harmonic vibration $(v=4)$ and the $\mathrm{C}-\mathrm{D}_{\mathrm{x}}$ fourth and fifth harmonic vibrations $(v=4,5)$ as compared to the interaction strength between $\mathrm{Yb}^{3+}$ and the $\mathrm{O}-\mathrm{H}$ third harmonic vibration $(v=3)$ and the $\mathrm{C}-\mathrm{H}_{\mathrm{x}}$ third and fourth harmonic vibrations $(v=3,4)$, as referred in Figure 2. The $\mathrm{O}-\mathrm{H}$ third harmonic vibrational mode (at approximately $9300-11,400 \mathrm{~cm}^{-1}$ [41,48]) matches the radiative transition from the first excited state ${ }^{2} F_{5 / 2}$ to the ground state ${ }^{2} F_{7 / 2}$ in $\mathrm{Yb}^{3+}$ ions (at approximately $9090-11,110 \mathrm{~cm}^{-1}$ as determined from the PL spectrum in Figure 1c), as shown in Figure 2. Also, the $\mathrm{C}-\mathrm{H}_{\mathrm{x}}$ third and fourth harmonic vibrational modes (at approximately $8400-9300 \mathrm{~cm}^{-1}$ and $11,200-12,400 \mathrm{~cm}^{-1}$ as inferred from FTIR spectra of $\mathrm{C}-\mathrm{H}_{\mathrm{x}}$ peaks measured in a-C:H film as displayed in Figure 3) match the radiative transitions in $\mathrm{Yb}^{3+}$ ions. The band indicated in Figure 2 is used to represent the highly varying bonding structure in the a-C matrix, which reflects the levels associated with the numerous combinations of nearest neighbors and the different local bonding environments. Accordingly, if excited $\mathrm{Yb}^{3+}$ ions are disturbed by $\mathrm{O}-\mathrm{H}$ and $\mathrm{C}-\mathrm{H}_{\mathrm{x}}$ oscillators, a non-radiative transition occurs. Considering the undistorted oscillator model [49], the transition probability between $\mathrm{Yb}^{3+}$ and the $\mathrm{O}-\mathrm{D}$ and $\mathrm{C}-\mathrm{D}_{\mathrm{x}}$ vibrational modes of the host deuterated $\mathrm{a}-\mathrm{C}$ film is lower than that between $\mathrm{Yb}^{3+}$ and the $\mathrm{O}-\mathrm{H}$ and $\mathrm{C}-\mathrm{H}_{\mathrm{x}}$ vibrational modes. This leads to an increase in the efficiency of the PL for a-C:D:F(Yb) films as shown in Figure 1c. The 8th and 9th harmonic vibrational modes of $\mathrm{C}-\mathrm{F}_{\mathrm{x}}$ overlap with the $\mathrm{Yb}^{3+}$ first excited state, however they play a negligible role on PL quenching as these vibrational modes are much higher $(v=8,9)$ compared to $\mathrm{O}-\mathrm{H}(v=3)$ and $\mathrm{C}-\mathrm{H}_{\mathrm{x}}(v=3,4)$ modes. Hence, by selecting the $\mathrm{Yb}(\mathrm{fod})_{3}$ metal-organic compound as the doping precursor instead of $\mathrm{Yb}(\mathrm{tmhd})_{3}$, tris(2,2,6,6-tetramethyl-3,5-heptanedionato)Ytterbium(+III) with chemical structure $\mathrm{Yb}\left(\mathrm{C}_{11} \mathrm{H}_{19} \mathrm{O}_{2}\right)_{3}$, the PL quenching by $\mathrm{C}-\mathrm{H}_{\mathrm{x}}$ is expected to be mitigated. 


\subsection{Effect of Substrate Temperature on a-C:D:F(Yb) Film}

The temperature of the growth surface was found to influence the concentration of $\mathrm{Yb}$ occluded in the a-C:D:F(Yb) films, and hence the PL efficiency. Table 1 lists the ratios of the atomic concentrations and the relative (and absolute) atomic concentrations of the relevant elements in the as-received stoichiometric $\mathrm{Yb}(\mathrm{fod})_{3}$ compound, and in the six a-C:D:F(Yb) films deposited under varying substrate temperatures as determined from XPS measurements. In comparing the a-C:D:F(Yb) film deposited at a substrate temperature of $60{ }^{\circ} \mathrm{C}$ to the stoichiometric $\mathrm{Yb}(\mathrm{fod})_{3}$ compound, a few results are observed. The $[\mathrm{O}] /[\mathrm{Yb}],[\mathrm{F}] /[\mathrm{Yb}]$, and $[\mathrm{C}] /[\mathrm{Yb}]$ ratios are approximately $8 \times, 1.65 \times$, and $2.2 \times$ smaller, respectively, in the film. This suggests that $\mathrm{Yb}$ incorporation is being promoted in the film. Moreover, fluorine incorporation is being promoted since the $[\mathrm{O}] /[\mathrm{F}]$ ratio is $4.8 \times$ larger in the film. The increase in the $\mathrm{F}$ concentration is attributed to the selective incorporation of $\mathrm{C}_{m} \mathrm{~F}_{n}$ fragments. This film also exhibits a surprising reduction in the amount of bonded carbon as witnessed by the lower $[\mathrm{C}] /[\mathrm{Yb}]$ and the higher $[\mathrm{F}] /[\mathrm{C}]$ ratios. One would expect the carbon concentration to increase since carbon can be sourced from $\mathrm{CD}_{4}$ or the $\mathrm{Yb}(\mathrm{fod})_{3}$ precursor. Evidently, significant dissociation of the $\mathrm{Yb}$ (fod $)_{3}$ compound occurs in the plasma environment. This is supported by the large variation in the atomic ratios $([\mathrm{C}] /[\mathrm{Yb}]=13.64,[\mathrm{O}] /[\mathrm{C}]=0.06,[\mathrm{~F}] /[\mathrm{C}]=0.93)$, as compared to the stoichiometric samples $([\mathrm{C}] /[\mathrm{Yb}]=30,[\mathrm{O}] /[\mathrm{C}]=0.20,[\mathrm{~F}] /[\mathrm{C}]=0.7)$. The bond energies may provide a possible explanation for the relative exclusion of $\mathrm{C}$ and $\mathrm{O}$ in the a-C:D:F(Yb) film grown at the substrate temperature of $60{ }^{\circ} \mathrm{C}$. The $\mathrm{C}-\mathrm{C}, \mathrm{C}-\mathrm{O}$, and $\mathrm{Yb}-\mathrm{O}$ bonds are expected to have a lower bond energy than $\mathrm{C}-\mathrm{F}, \mathrm{C}=\mathrm{C}$, and $\mathrm{C}=\mathrm{O}$ bonds. Hence, it is expected that they will be heavily dissociated within the plasma and as a result may not be incorporated in the resultant film.

Analyzing the XPS spectra for the films grown as the substrate temperature was varied from 60 to $150{ }^{\circ} \mathrm{C}$ yields a number of results. The $[\mathrm{F}]$ and $[\mathrm{Yb}]$ decrease monotonically with increasing substrate temperature. The $[\mathrm{C}]$ increases monotonically while the $[\mathrm{O}]$ shows a slightly increasing trend with increasing substrate temperature. The considerable loss of $[\mathrm{F}]$ and $[\mathrm{Yb}]$ with increasing substrate temperature is associated with a drop in the deposition of $\mathrm{C}_{\mathrm{m}} \mathrm{F}_{n}, \mathrm{YbO}_{x} \mathrm{C}_{m} \mathrm{~F}_{n}, \mathrm{Yb}$, and/or $\mathrm{YbO}_{x}$ molecular fragments. The relative variation in the drop of the $[\mathrm{F}]$ and $[\mathrm{Yb}]$ may be due to the temperature dependence of the sticking coefficient or the desorption rate of $\mathrm{Yb}$-containing fragments and F-containing fragments. Despite the decreasing [Yb] with increasing substrate temperature (black curve in Figure 4a), the relative PL intensity increases, peaks at a substrate temperature of $80{ }^{\circ} \mathrm{C}$, and then decreases as indicated in blue curve of Figure 4a. The increasing PL intensity with substrate temperature is attributed to the increasing $\mathrm{O}$ concentration and hence an increasing $[\mathrm{O}] /[\mathrm{Yb}]$ ratio as seen in Figure $4 \mathrm{~b}$. Hence, more $\mathrm{Yb}$ atoms are considered to be in the +3 state. Above a substrate temperature of $80{ }^{\circ} \mathrm{C}$ the $\mathrm{PL}$ intensity decreases even though the $[\mathrm{O}] /[\mathrm{Yb}]$ ratio continues to increase. This is due to the decreasing $[\mathrm{Yb}]$ with increasing substrate temperature (Figure 4a). At a substrate temperature of $150{ }^{\circ} \mathrm{C}$, the majority of the film is a-C:D with minute $\mathrm{F}$ and $\mathrm{Yb}$ concentrations as indicated in Table 1. A summary of the variation of the PL intensity with $\mathrm{Yb}$ concentration in a-C:D:F matrix is shown in Figure 4c. $I_{\text {nor }}$ increases linearly up to $\mathrm{Yb}$ concentration of approximately 2.1 at $\%$ and thereafter begins to drop until 3.6 at $\%$ at which point the PL becomes very weak. The latter suggests a reduction in lifetime $\Gamma$ beyond this point $[50]$ as result of energy transfer between optically active $\mathrm{Yb}^{3+}$ and $\mathrm{Yb}^{3+}$ ion pairs. 


\subsection{Yb Oxidation State in $a-C: D: F(Y b)$ Film}

The Yb4d XPS spectra of the thermally evaporated (abbreviated TE) Yb(fod) ${ }_{3}$ film, and three $\mathrm{a}-\mathrm{C}: \mathrm{D}: \mathrm{F}(\mathrm{Yb})$ samples with different $\mathrm{Yb}$ concentrations are compared in Figure $4 \mathrm{~d}$. Yb ions appear in the +2 state in the metal and in the +3 state or slightly mixed +2 and +3 states in the sesquioxide. $\mathrm{Yb}^{2+}$ metal clusters show two distinct peaks located at 183 and $192 \mathrm{eV}$ [51,52]. Also, the partially oxidized metal shows the two distinct peaks, as well as a small peak around 186-187 eV [52]. However, the fully oxidized $\mathrm{Yb}$ in the +3 state shows only one main peak around $186-187 \mathrm{eV}$ with the broad peaks in the higher-binding energy region [51,52]. The broad peaks are attributed to the $4 \mathrm{~d}$ levels in the $\mathrm{Yb}^{3+}$ ions forming multiplet splitting with electro-static coupling of a $4 \mathrm{~d}$ photohole to the unfilled valence shell of $\mathrm{Yb}^{3+}\left(4 f^{13}\right)$ [51,53]. From Figure 4d, the spectra reveal similar characteristics for all of the samples, implying the local environment of the incorporated $\mathrm{Yb}$ in a-C:D:F(Yb) films is similar to the $\mathrm{Yb}$ in the pristine $\mathrm{Yb}(\mathrm{fod})_{3}$ compound. More importantly, it confirms the preservation of the $\mathrm{Yb}^{3+}$ state in the $\mathrm{a}-\mathrm{C}(\mathrm{Yb})$ samples. However, the fact that the $[\mathrm{O}] /[\mathrm{Yb}]$ ratio is less than six (shown in Table 1), as is the case for the pristine $\mathrm{Yb}$ (fod $)_{3}$ powder, suggests that some $\mathrm{Yb}$ ions may have undergone a shift in their electronic structure (the ${ }^{2} F_{5 / 2}$ and/or ${ }^{2} F_{7 / 2}$ energy levels) or may be optically inactive. A shift in the electronic structure would be supported by the larger width of the observed PL signal as compared to the reported widths from $\mathrm{Yb}$ doped ceramic [11,14,18,30], oxide [21,22,24,25] based host films, and $\mathrm{Yb}_{2} \mathrm{O}_{3}$ crystalline films [33]. This wider luminescence spectra were also observed in $\mathrm{Yb}$ doped AlN films, where the host AlN films are essentially amorphous in form with AlN nanocrystals embedded in the matrix [54]. Nevertheless, the Yb4d XPS spectra suggest the $\mathrm{Yb}^{3+}$ state is mostly preserved in the a-C:D:F(Yb) films, leading to the observed PL.

\subsection{Structural Analyses of $a-C: D: F(Y b)$ Film}

Detailed XPS analyses were performed to examine the bonding details of the resultant a-C:D:F(Yb) film. In Figure $5 \mathrm{a}$, the deconvoluted $\mathrm{C} 1 \mathrm{~s}$ spectra indicate the majority of carbon bonds are $\mathrm{C}-\mathrm{C}$ and/or $\mathrm{C}-\mathrm{D} / \mathrm{C}-\mathrm{H}$, with some $\mathrm{C}-\mathrm{F}, \mathrm{C}-\mathrm{O}$ and/or $\mathrm{C}-\mathrm{CF}$, and very few $\mathrm{C}=\mathrm{O}$ and/or $\mathrm{C}-\mathrm{F}_{\mathrm{x}}$ bonds in the $\mathrm{a}-\mathrm{C}: \mathrm{D}: \mathrm{F}(\mathrm{Yb})$ film. The deconvoluted $\mathrm{F} 1 \mathrm{~s}$ spectra displayed in Figure $5 \mathrm{~b}$ show a small concentration of $\mathrm{YbF}_{\mathrm{x}}$ bonds exist in the a-C:D:F(Yb) film, while the majority of $\mathrm{F}$ atoms are bonded to carbon as $\mathrm{C}-\mathrm{F}$ bonds, with some $\mathrm{C}-\mathrm{F}_{2}$ bonds and a minute amount of $\mathrm{C}-\mathrm{F}_{3}$ bonds. Note that the fitting error $\left(\Sigma \chi^{2}\right)$ would be $33 \%$ higher without adding the $\mathrm{YbF}_{\mathrm{x}}$ bond peak at $683.6 \mathrm{eV}$ during the $\mathrm{F} 1 \mathrm{~s}$ deconvolution process. This suggests that the probability of $\mathrm{Yb}$ bonding in the optically active +3 state could be increased by formation of the $\mathrm{Yb}-\mathrm{F}_{\mathrm{x}}$ bonds, in addition to the expected +3 state as in the pristine $\mathrm{Yb}-\mathrm{O}$ bonds of the $\mathrm{Yb}(\mathrm{fod})_{3}$ compound. This additional bonding environment could further promote the luminescence efficiency of the $\mathrm{a}-\mathrm{C}(\mathrm{Yb})$ film, as demonstrated by the observed luminescence from $\mathrm{YbF}_{3}$ nanoparticles [55-57]. The different percentages of carbon and fluorine related bonds, as depicted in Figure 5, imply that significant dissociation of the $\mathrm{Yb}(\mathrm{fod})_{3}$ compound occurs in the plasma environment. For instance, plasma dissociation of the $\mathrm{C}-\mathrm{F}_{3}$ and $\mathrm{C}-\mathrm{F}_{2}$ groups into $\mathrm{C}-\mathrm{F}$ is shown by the decrease of the $\mathrm{F} 1 \mathrm{~s} \mathrm{C}-\mathrm{F}_{3}$ and $\mathrm{C}-\mathrm{F}_{2}$ peaks in the a-C:D:F(Yb) film in Figure $5 \mathrm{~b}$ compared to the $\mathrm{TE} \mathrm{Yb}(\mathrm{fod})_{3}$ film in Figure $5 \mathrm{~d}$. This is also supported by the increase in the $\mathrm{C}-\mathrm{F}$ bond for the $\mathrm{C} 1 \mathrm{~s}$ peak, as well as the decrease in the $\mathrm{C}=\mathrm{O}$ and/or $\mathrm{C}-\mathrm{F}_{\mathrm{x}}$ and $\mathrm{C}-\mathrm{O}$ and/or $\mathrm{C}-\mathrm{CF}$ peak, relative to the $\mathrm{TE} \mathrm{Yb}(\text { fod })_{3}$ film. Note that no $\mathrm{C} 1 \mathrm{~s} \mathrm{C}-\mathrm{Yb}$ 
peak was observed. Thus, the resultant $\mathrm{a}-\mathrm{C}: \mathrm{D}: \mathrm{F}(\mathrm{Yb})$ film contains $\mathrm{Yb}^{3+}$ ions bonded to $\mathrm{O}$ and/or $\mathrm{F}$ (i.e., $\mathrm{YbF}_{3}, \mathrm{YbFO}_{2}, \mathrm{YbF}_{2} \mathrm{O}$, and $\mathrm{YbO}_{3}$ ), and is surrounded by a variety of local environments (with varying sizes of the $\mathrm{Yb}^{3+}$ sites) due to the structural flexibility of the a-C matrix. Consequently, these structural observations may confirm the observed wider FWHM PL signal shown in Figure 1c, compared to other $\mathrm{Yb}$ doped ceramic [11,14,18,30] and oxide based materials [21,22,24,25].

Figure 4. (a) The Yb concentration (solid black circle) and normalized PL peak intensity, $I_{n o r},($ solid blue circle) as a function of the substrate temperature for a-C:D:F(Yb) films deposited at an RF power of $60 \mathrm{~W}$. The normalized PL peak intensity is shown to depend critically on the (b) $[\mathrm{O}] /[\mathrm{Yb}]$ ratio; and $(\mathbf{c})[\mathrm{Yb}]$. The lines are guides to the eye. $I_{\text {nor }}$ is defined as the PL intensity peaking at $\sim 987 \mathrm{~nm}$ normalized to the a-C:D:F(Yb) film thickness; (d) Yb4d XPS spectra of the three a-C:D:F(Yb) films, and TE Yb(fod) ${ }_{3}$ film (thermally evaporated $\mathrm{Yb}(\mathrm{fod})_{3}$ compound in the vacuum chamber with $\mathrm{CD}_{4}$ precursor gas flowing without plasma ignition). The curves have been shifted vertically for clarity of presentation.

(a)

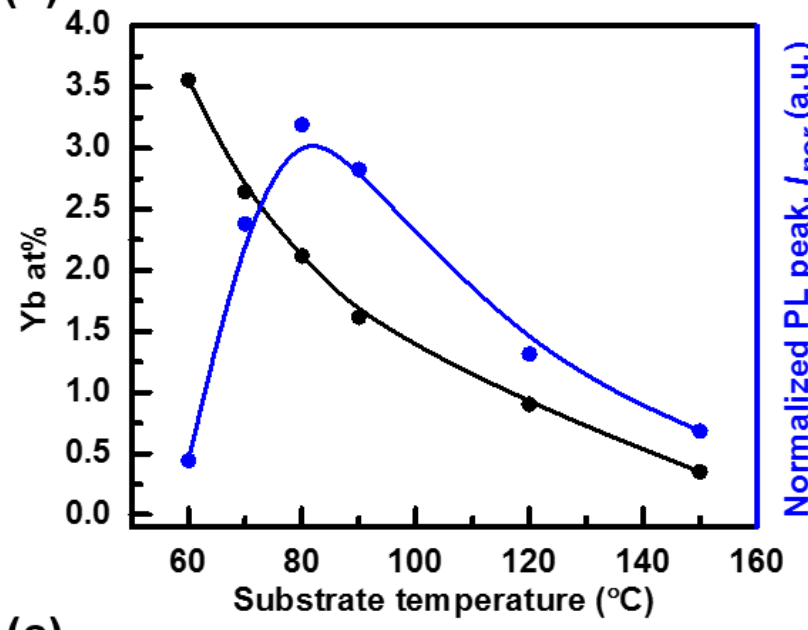

(c)

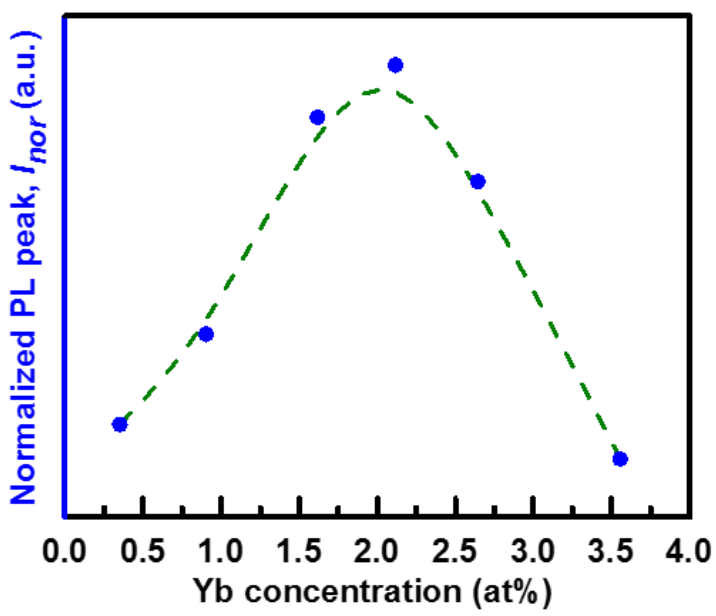

(b)

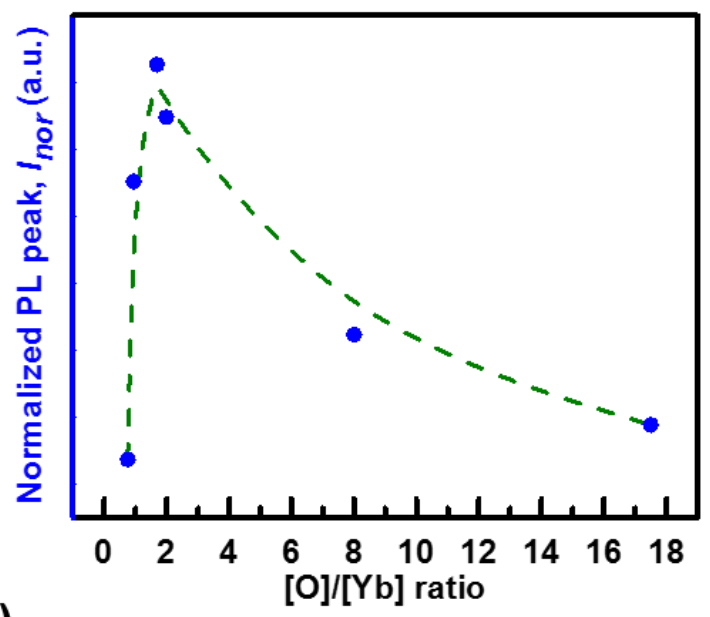

(d)

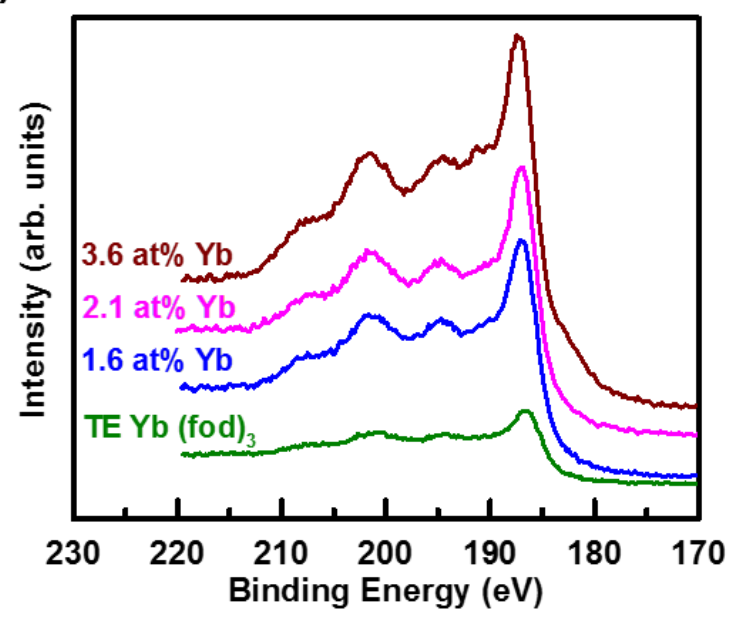


Figure 5. Deconvoluted XPS (a) $\mathrm{C} 1 \mathrm{~s}$ and (b) F1s spectra of the a-C:D:F(Yb) film with maximum $I_{\text {nor }}$ prepared using RF power of $60 \mathrm{~W}$, precursor gas flow rate of $20 \mathrm{sccm}$, deposition pressure of 60 mTorr, substrate temperature of $80^{\circ} \mathrm{C}$, and $\mathrm{Yb}(\mathrm{fod})_{3}$ powder evaporated at a temperature of $110{ }^{\circ} \mathrm{C}$; and (c) $\mathrm{C} 1 \mathrm{~s}$ and (d) $\mathrm{F} 1 \mathrm{~s}$ spectra of the $\mathrm{TE}$ $\mathrm{Yb}(\mathrm{fod})_{3}$ film.

(a)

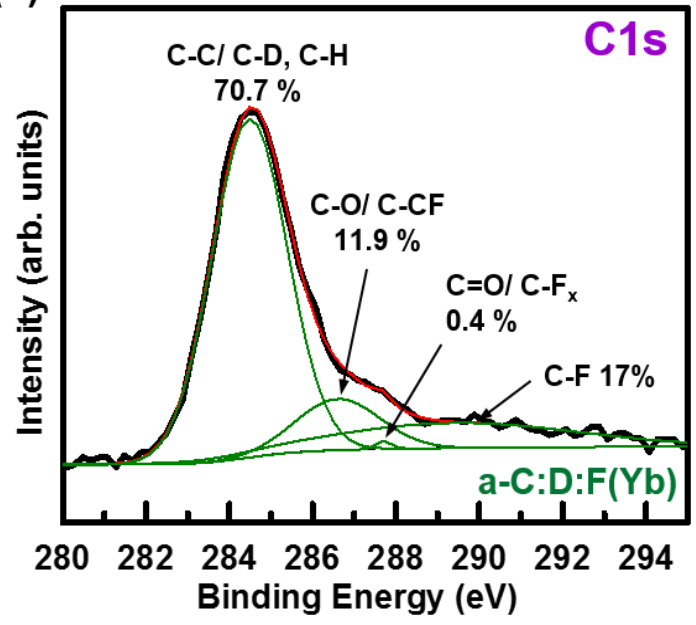

(c)

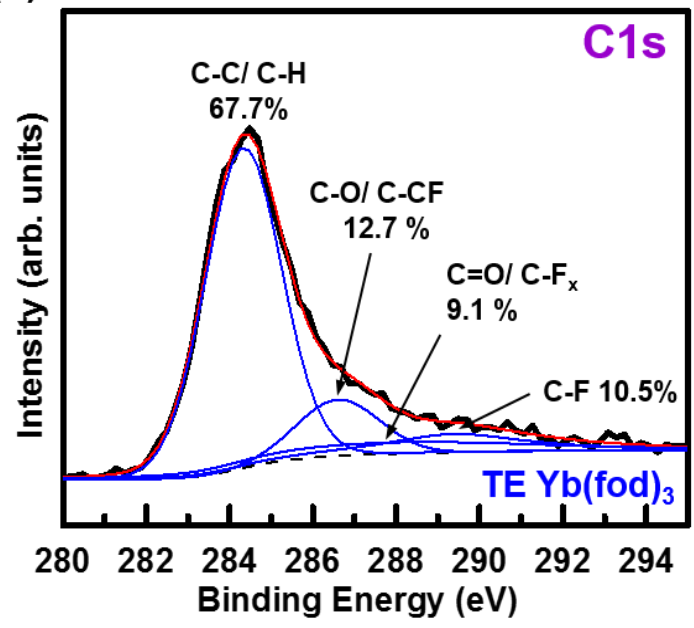

(b)

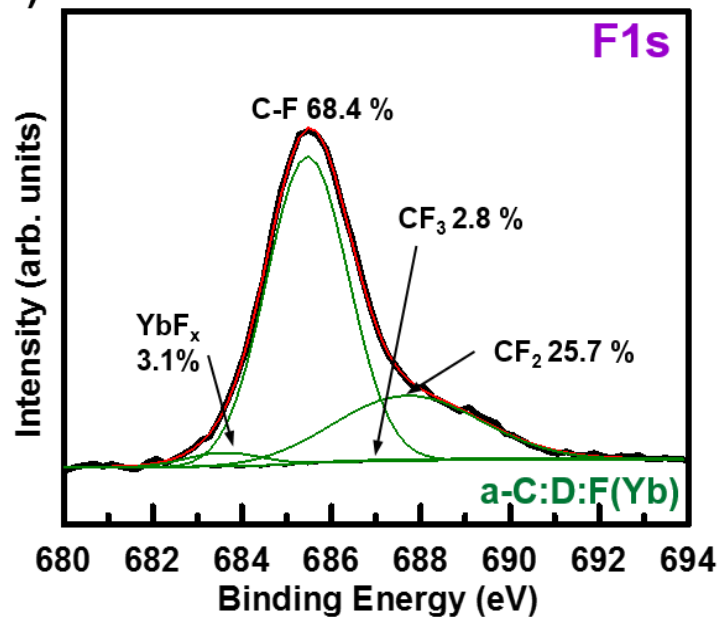

(d)

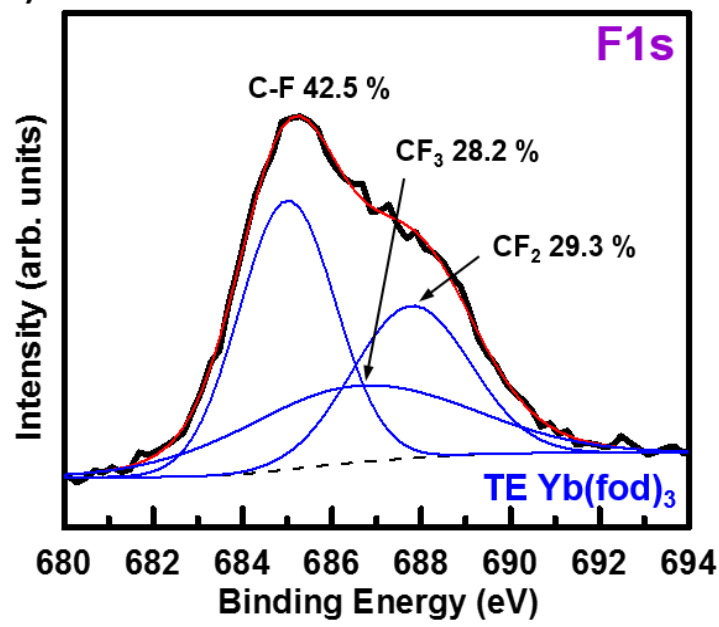

The XPS measurements revealed that some samples contained a high fraction of fluorine. In order to probe the changes in the optical properties of the host a-C film due to fluorination, fluorinated a-C:D (a-C:D:F) host films were prepared from deuterated methane $\left(\mathrm{CD}_{4}\right)$ and tetrafluoromethane $\left(\mathrm{CF}_{4}\right)$ mixtures. It was observed that as the relative $\mathrm{F}$ at $\%$ increases (i.e., $\mathrm{CF}_{4} /\left[\mathrm{CF}_{4}+\mathrm{CD}_{4}\right]$ ratio increases), the $E_{04}$ optical bandgap of the resultant a-C:D:F films decreases (data now shown here). Robertson [39] describes the microstructures of a-C as a continuous network of $s p^{3}$ bonded carbon atoms (predominately $\mathrm{C}-\mathrm{C}$ or a mixture of $\mathrm{C}-\mathrm{C}$ and $\mathrm{C}-\mathrm{H}$ ) with $s p^{2}$ bonded carbon localized clusters (the number and size of the $\mathrm{C}=\mathrm{C}$ ) embedded within the network. The $s p^{3}$ bond configuration forms $\sigma-\sigma^{*}$ bands and the $s p^{2}$ sites create $\pi-\pi^{*}$ bands by forming the localized states. The size and quantity of the $s p^{2}$ clusters dominate the film's optical properties. Accordingly, the increasing $\% s p^{2}$ content in the film implies an increase in the localized density of states lying deeper in the gap. Thus, the decrease in the optical bandgap $E_{04}$ as the relative $\mathrm{F}$ at $\%$ increases in the films could be attributed to the increase in $\% s p^{2}$ bonding in the film [58-60]. 
Although the $E_{04}$ of the a-C(Yb) films cannot be accessed at this moment, samples 1 and 2, as shown in Table 1, represent a-C(Yb) films grown at the substrate temperature of 60 and $70{ }^{\circ} \mathrm{C}$, and along with the PL shown in Figure 4a, it could be inferred that it appears that these films have lower $E_{04}$ compared to that of sample 3 . This is due to higher incorporation of $\mathrm{F}$ [58-60] and $\mathrm{Yb}[61,62]$ concentrations than those in sample 3 as seen in Table 1 . As the relative $\mathrm{F}$ at \% increases in the films the $E_{04}$ optical bandgap was observed to decrease (data not shown here), which could be attributed to the increase in $\% s p^{2}$ bonding in the film giving rise to a localized density of states lying deeper in the gap [58-60]. Moreover, with higher $\mathrm{Yb}$ incorporation, \% $s p^{2}$ is expected to further increase considering the observations of Er doped or Er oxide doped diamond like carbon films reported by Foong et al. [61,62]. Thus the higher $\% s p^{2}$ in samples 1 and 2 of the a-C(Yb) films might be another minor factor that contributes toward the lower PL intensity observed in addition to the concentration quenching effect from the high $\mathrm{Yb}$ concentration. Accordingly, higher $\% s p^{2}$ could result in a higher probability of photoelectrons for non-radiative recombination in the a-C:D host, leading to a lower probability of photoelectrons transferring from the a-C:D host to $\mathrm{Yb}^{3+}$ ions and further emitting $1 \mu \mathrm{m}$ photons at room temperature. With respect to the change in film optical properties after incorporation of the $\mathrm{Yb}$ compound, the refractive index $n$ and extinction coefficient $k$ are expected to increase based on the results obtained from rare-earth ions doped $\mathrm{PbTiO}_{3}$ thin films prepared by sol-gel method [63]. The role of $\% s p^{2}$ (the number and size of the $\mathrm{C}=\mathrm{C}$ ) and energy transfer mechanism between $\mathrm{Yb}^{3+}$ ions and the host a-C are still under investigation via application of multiple laser excitations (488 and $980 \mathrm{~nm}$ ) in addition to the presently employed $532 \mathrm{~nm}$ laser source.

\section{Experimental Section}

\subsection{RF-PEMOCVD and Sample Preparation}

A capacitively coupled RF-PEMOCVD system was deployed to deposit a-C(Yb) films. An ac-powered thermal evaporator situated next to the RF-powered electrode, inside the deposition chamber was utilized to in situ dope the $\mathrm{Yb}$ metal-organic compound while the a-C film deposition proceeds. The technique has been demonstrated to provide the capability of doping Er in a vertically uniform profile. As well, this technique provides independent control of the Er concentration profile and the optical properties of the host material [44,64].

For a-C(Yb) films, the substrate temperature was varied from 60 to $150{ }^{\circ} \mathrm{C}$. The hydrocarbon gas flow rate was $20 \mathrm{sccm}$, chamber pressure was at $60 \mathrm{mTorr}$, and the RF power was kept constant at $60 \mathrm{~W}$. Double-side polished crystalline silicon substrates with resistivity of more than $1000 \mathrm{ohm}-\mathrm{cm}$ were subjected to the standard CMOS cleaning procedure before being loaded into the chamber. Methane $\left(\mathrm{CH}_{4}\right)$ with purity of $99.999 \%$ and tetrafluoromethane $\left(\mathrm{CF}_{4}\right)$ with purity of $99.996 \%$ were purchased from Linde Canada Limited. Deuterated methane $\left(\mathrm{CD}_{4}\right)$ with isotopic purity of 99 atom \% D was purchased from Sigma-Aldrich (St. Louis, MO, USA).

\subsection{Incorporated Yb Metal-Organic Compound}

The $\mathrm{Yb}$ metal-organic compound tris(6,6,7,7,8,8,8-heptafluoro-2,2-dimethyl-3,5-octanedionate) Ytterbium (+III), abbreviated ( $\left.\mathrm{Yb}(\text { fod })_{3}\right)$, having the chemical structure $\mathrm{Yb}\left(\mathrm{C}_{10} \mathrm{H}_{10} \mathrm{~F}_{7} \mathrm{O}_{2}\right)_{3}$ as illustrated 
in Figure 6, was selected as the doping candidate for $\mathrm{a}-\mathrm{C}(\mathrm{Yb})$ films. The $\mathrm{Yb}$ in the $\mathrm{Yb}(\mathrm{fod})_{3}$ compound is coordinated by six oxygen atoms, which represents a similar bonding environment to $\mathrm{Yb}(\mathrm{tmhd})_{3}$. $\mathrm{Yb}$ (tmhd) $)_{3}$ has been employed as the precursor to dope $\mathrm{Yb}_{2} \mathrm{O}_{3}$ in $\mathrm{Y}_{2} \mathrm{O}_{3}$ films by atomic layer deposition method [65] in order to maintain the optically active $\mathrm{Yb}^{3+}$ state. Accordingly, it was presumed that the optically active $\mathrm{Yb}^{3+}$ ions can be preserved under appropriate deposition conditions in the present study. In addition, it has been previously demonstrated that the $\mathrm{Er}^{3+}$ optical activity can be partially preserved without the need of a post-deposition annealing step by utilizing the $\operatorname{Er}(\text { fod })_{3}$ compound in the RF-PEMOCVD method [44,64]. The hydrocarbon ligands of the Yb metal-organic compound are expected to promote a high $\mathrm{Yb}$ concentration in the a-C host matrix as its structure matches the internal structure of the a-C host matrix. In this work, a controlled vapor flux of the $\mathrm{Yb}$ (fod $)_{3}$ compound is introduced by thermal evaporation at $110{ }^{\circ} \mathrm{C}$. The vapor flux is mixed with the hydrocarbon plasma for a-C(Yb) film formation. The $\mathrm{Yb}(\text { fod })_{3}$ powder was obtained from Strem Chemicals Inc. (Newburyport, MA, USA) and was loaded into the vacuum chamber without any special treatment.

Figure 6. Illustration of the $\mathrm{Yb}$ metal-organic compound, $\mathrm{Yb}(\mathrm{fod})_{3}$, with chemical structure $\mathrm{Yb}\left(\mathrm{C}_{10} \mathrm{H}_{10} \mathrm{O}_{2} \mathrm{~F}_{7}\right)_{3}$.

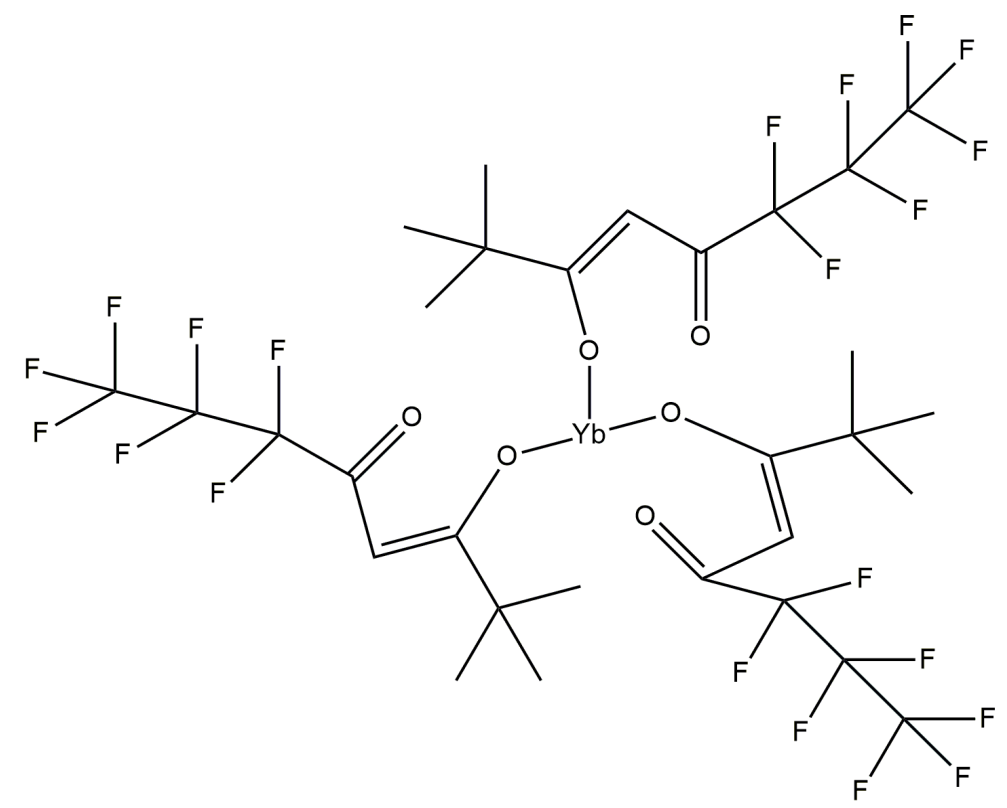

\subsection{Film Characterization}

\subsubsection{Photoluminescence}

Photoluminescence spectra of a-C(Yb) films were collected at room temperature to verify the luminescence property of the $\mathrm{Yb}$ in the $\mathrm{a}-\mathrm{C}(\mathrm{Yb})$ films. A continuous wave diode-pumped solid-state $532 \mathrm{~nm}$ laser with a power density of $20 \mathrm{~mW} / \mathrm{mm}^{2}$ was used as the excitation source. A thermoelectrically cooled InGaAs photodiode, 800-1700 nm detection range, with standard lock-in technique was employed. A single pass monochromator with resolution bandwidth of $2 \mathrm{~nm}$ was utilized to disperse the emitted PL. $I_{\text {nor }}$ indicated in Figure 4 is defined as the PL intensity peaking at $\sim 987 \mathrm{~nm}$ and normalized to the respective $\mathrm{a}-\mathrm{C}(\mathrm{Yb})$ film thickness indicated in Table 1. 


\subsubsection{X-ray Photoelectron Spectroscopy}

X-ray photoelectron spectroscopy (XPS) was employed to quantitatively characterize the elemental composition and chemical structure of $\mathrm{a}-\mathrm{C}(\mathrm{Yb})$ films. The XPS spectra were collected from the surface of the sample using a monochromatic $\mathrm{Al} \mathrm{K \alpha} \mathrm{X}$-ray source in a Thermo Scientific K-Alpha spectrometer (ThermoFisher Scientific, Waltham, MA, USA) with an ultrahigh vacuum of the order of $10^{-9}$ Torr. The spectra were calibrated relative to a charge reference of adventitious carbon with a core level binding energy of $284.5 \mathrm{eV}$, while for curve fitting we used published values of binding energies and Gaussian decompositions with Smart background.

\subsubsection{Fourier Transform Infrared Spectroscopy}

The relative wavenumber/wavelength positions and range of energy levels of the first vibrational modes $(v=1)$ of $C-H_{x}, C-D_{x}$, and $C-F_{x}$ bonds, shown in Figure 2, were obtained from the absorption peaks of the host a-C:H, a-C:D, and a-C:D:F films measured by Fourier Transform Infrared Spectroscopy (FTIR) technique as displayed in Figure 3. From Figure 3, it can be seen that the first vibrational modes $(v=1)$ of $C-H_{x}$ and $C-D_{x}$ bonds are located at $2800-3100 \mathrm{~cm}^{-1}$ (blue curve) and $2000-2300 \mathrm{~cm}^{-1}$ (green curve). Thus, it can be inferred that the third $(v=3)$ and fourth $(v=4)$ harmonic vibrational modes of $\mathrm{C}-\mathrm{H}_{\mathrm{x}}$ peaks are at approximately $8400-9300 \mathrm{~cm}^{-1}$ and $11,200-12,400 \mathrm{~cm}^{-1}$, which match the radiative transition from the first excited state ${ }^{2} F_{5 / 2}$ to the ground state ${ }^{2} F_{7 / 2}$ in $\mathrm{Yb}^{3+}$ ions (at approximately $9090-11,110 \mathrm{~cm}^{-1}$ as determined from the PL spectrum in Figure 1c) as shown in Figure 2. Also, the fourth and fifth harmonic vibrations $(v=4,5)$ of $C-D_{x}$ bonds can be inferred to be at $8000-9200 \mathrm{~cm}^{-1}$ and $10,000-11,500 \mathrm{~cm}^{-1}$, which match the radiative transition in $\mathrm{Yb}^{3+}$ ions as well. The first vibrational modes $(v=1)$ of $\mathrm{O}-\mathrm{H}$ and $\mathrm{O}-\mathrm{D}$ are approximately located at $3100-3800 \mathrm{~cm}^{-1}$ centered at $3450 \mathrm{~cm}^{-1}$ and $2150-2850 \mathrm{~cm}^{-1}$ centered at $2500 \mathrm{~cm}^{-1}$ from the cited reference papers $[41,48]$. Thus, it can be inferred that the $\mathrm{O}-\mathrm{H}$ third harmonic vibrational mode $(v=3)$ is at approximately $9300-11,400 \mathrm{~cm}^{-1}$ and the O-D third and fourth harmonic vibrational mode $(v=3,4)$ are at approximately $6450-8550 \mathrm{~cm}^{-1}$ and $8600-11,400 \mathrm{~cm}^{-1}$.

Furthermore, the first set of harmonic vibrational mode of $C-F_{x}$ is at $900-1400 \mathrm{~cm}^{-1}$ as observed in Figure 3 (orange curve). Thus, it can be inferred that the 8 th and 9 th harmonic vibrational modes are at $7200-11,200 \mathrm{~cm}^{-1}$ and $8100-12,600 \mathrm{~cm}^{-1}$ (not shown in Figure 2), which also overlap with the $\mathrm{Yb}^{3+}$ first excited state. However, they play a negligible role on PL quenching as these vibrational modes are much higher $(v=8,9)$ compared to $\mathrm{O}-\mathrm{H}(v=3)$ and $\mathrm{C}-\mathrm{H}_{\mathrm{x}}(v=3,4)$ modes. Moreover, the darker sections of the band in Figure 2 signify a higher absorption coefficient. Hence, the dark band indicates the energy distribution of the vibrational levels.

The FTIR spectra were characterized using a Perkin Elmer 2000 spectrometer (PerkinElmer, Waltham, MA, USA) with a resolution of $4 \mathrm{~cm}^{-1}$. The transmission spectra were background corrected for the interference patterns emerging due to multiple reflections in the film. The absorption was determined using the following relation:

$$
\alpha(v)=-\frac{1}{d} \ln T
$$

where $\alpha(v)$ is the absorption coefficient; $d$ is the thickness of the film; and $T$ is the normalized transmission of the a-C film with the background removed. 


\subsubsection{Spectroscopic Ellipsometry}

The optical bandgaps $E_{04}$ of the host deuterated/fluorinated amorphous carbon (a-C:D:F) films were probed through spectroscopic ellipsometry. The measurements were carried out using an UV-Vis-NIR spectroscopic ellipsometer (Semilab, Budapest, Hungary). The spectra were analyzed by regression fitting using the linear Levenberg-Marquardt algorithm method with a maximum of 1000 iterations using a three-layer optical structure comprising void (ambient)/a-C layer/c-Si substrate. The five constants of Forouhi-Bloomer dispersion model [66] and thickness of the a-C layer were allowed to vary during the fitting process. The optical bandgap $E_{04}$, defined as the photon energy at which the absorption coefficient $\alpha(=4 \pi k / \lambda)$ is equal to $10^{4} \mathrm{~cm}^{-1}$, was determined from the extinction coefficient $k$; $\lambda$ is the wavelength.

\section{Conclusions}

The in situ growth of $\mathrm{Yb}$-doped a-C thin films on Si substrates at low temperature $\left(<200{ }^{\circ} \mathrm{C}\right)$ was successfully demonstrated by a simple one-step RF-PEMOCVD system. Room temperature PL at a wavelength of around $1 \mu \mathrm{m}$ was observed from these $\mathrm{a}-\mathrm{C}(\mathrm{Yb})$ films. A subsequent high temperature post-deposition annealing procedure was not required. This is a result of the direct incorporation of the optically active $\mathrm{Yb}^{3+}$ ions from the specially selected $\mathrm{Yb}(\mathrm{fod})_{3}$ metal-organic compound. The PL was enhanced by a factor of four due to the use of deuteration as opposed to hydrogenation of the a-C host. This served to lower the interaction strength between the excited $\mathrm{Yb}^{3+}$ and the neighboring harmonic vibrational modes. Moreover, fluorination of the a-C host may assist in the suppression of the PL quenching effect through the partial substitution of $\mathrm{C}-\mathrm{H}$ bonds with $\mathrm{C}-\mathrm{F}$ bonds.

The substrate temperature was varied from 60 to $150{ }^{\circ} \mathrm{C}$, and was shown to greatly influence the relative deposition rates of the plasma dissociated metal-organic species. It was observed that the relative PL intensity increases, peaks at a substrate temperature of $80{ }^{\circ} \mathrm{C}$, and then decreases. The increasing $\mathrm{PL}$ intensity is attributed to an increase in $[\mathrm{O}] /[\mathrm{Yb}]$ ratio, leading to more $\mathrm{Yb}$ atoms in the +3 state. Above a substrate temperature of $80{ }^{\circ} \mathrm{C}$ the $[\mathrm{O}] /[\mathrm{Yb}]$ ratio continues to increase, however the $\mathrm{PL}$ decreases. This is due to the considerable loss of the $[\mathrm{Yb}]$, which is associated with a drop in the temperature-dependent deposition of $\mathrm{YbO}_{x} \mathrm{C}_{m} \mathrm{~F}_{n}, \mathrm{Yb}$, and/or $\mathrm{YbO}_{x}$ molecular fragments. The relative $\mathrm{PL}$ intensity increases linearly with the $\mathrm{Yb}$ concentration up to a $[\mathrm{Yb}]$ of approximately $2.1 \mathrm{at} \mathrm{cm}^{-1}$. Thereafter the PL intensity begins to drop, suggesting a severe energy transfer between active $\mathrm{Yb}^{3+}$ and $\mathrm{Yb}^{3+}$ ion pairs beyond this point.

The Yb4d XPS spectra indicated that the environment of the incorporated $\mathrm{Yb}$ in a-C(Yb) films is similar to the $\mathrm{Yb}$ in the pristine $\mathrm{Yb}(\mathrm{fod})_{3}$ compound. Although, the fact that the $[\mathrm{O}] /[\mathrm{Yb}]$ ratio is less than six suggests some $\mathrm{Yb}$ ions may have their electronic structure shifted (the ${ }^{2} F_{5 / 2}$ and/or ${ }^{2} F_{7 / 2}$ energy levels) or have become optically inactive. By examining the $\mathrm{C} 1 \mathrm{~s}$ and $\mathrm{F} 1 \mathrm{~s}$ deconvoluted XPS spectra in detail, the $\mathrm{Yb}^{3+}$ ions in the $\mathrm{a}-\mathrm{C}(\mathrm{Yb})$ films are found to be bonded to $\mathrm{O}$ and/or $\mathrm{F}$ (i.e., $\mathrm{YbF}_{3}, \mathrm{YbFO}_{2}$, $\mathrm{YbF}_{2} \mathrm{O}, \mathrm{YbO}_{3}$ ). The formation of the $\mathrm{Yb}-\mathrm{F}_{\mathrm{x}}$ bonds increases the probability of $\mathrm{Yb}$ bonding in the optically active +3 state, which may promote the luminescence efficiency of a-C(Yb) films. However, the relatively high $\mathrm{F}$ concentration in the host a-C matrix could lead to an increase in the de-excitation 
pathways. This is due to the smaller band gap or the increased states within the band gap typically found in a-C:F materials.

In summary, the a-C:D:F(Yb) films synthesized by the RF-PEMOCVD method at low temperatures $\left(<200{ }^{\circ} \mathrm{C}\right)$, exhibit room temperature luminescence owing to direct incorporation of $\mathrm{Yb}^{3+}$ ions. Also, luminescence is enhanced by the substitution of $\mathrm{C}-\mathrm{D}_{\mathrm{x}}, \mathrm{C}-\mathrm{F}_{\mathrm{x}}$, and $\mathrm{O}-\mathrm{D}$ bonds with $\mathrm{C}-\mathrm{H}_{\mathrm{x}}$ and $\mathrm{O}-\mathrm{H}$ bonds. The wide FWHM observed is due to the various local bonding environments. These properties suggest that a-C:D:F(Yb) may be a promising material for active photonic devices to be integrated with the current Si CMOS platform.

\section{Acknowledgments}

This work was supported by the Natural Sciences and Engineering Research Council of Canada (NSERC) Discovery grants, the NSERC CREATE program in Nanoscience and Nanotechnology, and the Departments of Electrical and Computer Engineering and Materials Science and Engineering at the University of Toronto. The authors also acknowledge valuable help from Davit Yeghikyan and Tome Kosteski with the RF-PEMOCVD system.

\section{Author Contributions}

Hui-Lin Hsu and Keith R. Leong planned and conducted most of the experiments related to this study under the supervision of Li Qian and Nazir P. Kherani. The principal contributions of I-Ju Teng, Jenh-Yih Juang and Sheng-Rui Jian comprised photoluminescence characterizations and XPS analyses. Michael Halamicek assisted with the Fourier Transform InfraRed Spectroscopy measurements. The article was written and edited by Hui-Lin Hsu, Keith R. Leong, Li Qian, and Nazir P. Kherani.

\section{Conflicts of Interest}

The authors declare no conflict of interest.

\section{References}

1. Paniccia, M. Integrating silicon photonics. Nat. Photonics 2010, 4, 498-499.

2. Polman, A. Erbium implanted thin film photonic materials. J. Appl. Phys. 1997, 82, 1-39.

3. Polman, A.; van Veggel, F.C.J.M. Broadband sensitizers for erbium-doped planar optical amplifiers: Review. J. Opt. Soc. Am. B: Opt. Phys. 2004, 21, 871-892.

4. Xiao, H. Introduction to Semiconductor Manufacturing Technology, 2nd ed.; SPIE Press: Bellingham, WA, USA, 2012.

5. Taira, T.; Saikawa, J.; Kobayashi, T.; Byer, R.L. Diode-pumped tunable Yb:YAG miniature lasers at room temperature: Modeling and experiment. IEEE J. Sel. Top. Quantum Electron. 1997, 3, 100-104.

6. Antognini, A.; Schuhmann, K.; Amaro, F.D.; Biraben, F.; Dax, A.; Giesen, A.; Graf, T.; Hansch, T.W.; Indelicato, P.; Julien, L.; et al. Thin-disk Yb:YAG oscillator-amplifier laser, ASE, and effective Yb:YAG lifetime. IEEE J. Quantum Electron. 2009, 45, 993-1005. 
7. Sumida, D.S.; Fan, T.Y. Room-temperature 50-mJ/pulse side-diode-pumped Yb:YAG laser. Opt. Lett. 1995, 20, 2384-2386.

8. Yang, P.; Deng, P.; Yin, Z. Concentration quenching in Yb:YAG. J. Lumin. 2002, 97, 51-54.

9. Dong, J.; Bass, M.; Mao, Y.; Deng, P.; Gan, F. Dependence of the $\mathrm{Yb}^{3+}$ emission cross section and lifetime on temperature and concentration in yttrium aluminum garnet. J. Opt. Soc. Am. B: Opt. Phys. 2003, 20, 1975-1979.

10. Jacquemet, M.; Jacquemet, C.; Janel, N.; Druon, F.; Balembois, F.; Georges, P.; Petit, J.; Viana, B.; Vivien, D.; Ferrand, B. Efficient laser action of Yb:LSO and Yb:YSO oxyorthosilicates crystals under high-power diode-pumping. Appl. Phys. B 2005, 80, 171-176.

11. Ubizskii, S.B.; Matkovskii, A.O.; Melnyk, S.S.; Syvorotka, I.M.; Muller, V.; Peters, V.; Petermann, K.; Beyertt, A.; Giesen, A. Optical properties of epitaxial YAG:Yb films. Phys. Status Solidi A 2004, 201, 791-797.

12. Wang, H.M.; Simmonds, M.C.; Huang, Y.Z.; Rodenburg, J.M. Synthesis of nanosize powders and thin films of Yb-doped YAG by sol-gel methods. Chem. Mater. 2003, 15, 3474-3480.

13. Shimoda, T.; Ishida, Y.; Adachi, K.; Obara, M. Fabrication of highly ytterbium $\left(\mathrm{Yb}^{3+}\right)$-doped YAG thin film by pulsed laser deposition. Opt. Commun. 2001, 194, 175-179.

14. Thibault, F.; Pelenc, D.; Chambaz, B.; Couchaud, M.; Petit, J.; Viana, B. Growth and characterization of $\mathrm{Yb}^{3+}$ doped $\mathrm{Y}_{2} \mathrm{SiO}_{5}$ layers on $\mathrm{Y}_{2} \mathrm{SiO}_{5}$ substrate for laser applications. Opt. Mater. 2008, 30, 1289-1296.

15. Denoyer, A.; Jandl, S.; Thibault, F.; Pelenc, D. Optical effects of annealing on Yb-doped $\mathrm{Y}_{2} \mathrm{SiO}_{5}$ thin films. J. Phys.: Condens. Matter 2007, 19, doi:10.1088/0953-8984/19/15/156222.

16. Denoyer, A.; Levesque, Y.; Jandl, S.; Guillot-Noel, O.; Goldner, P.; Viana, B.; Thibault, F.; Pelenc, D. Crystal field study of ytterbium doped $\mathrm{Lu}_{2} \mathrm{SiO}_{5}$ and $\mathrm{Y}_{2} \mathrm{SiO}_{5}$ under a magnetic field. J. Phys.: Condens. Matter 2008, 20, doi:10.1088/0953-8984/20/12/125227.

17. Romanyuk, Y.E.; Borca, C.N.; Pollnau, M.; Rivier, S.; Petrov, V.; Griebner, U. Yb-doped $\mathrm{KY}\left(\mathrm{WO}_{4}\right)_{2}$ planar waveguide laser. Opt. Lett. 2006, 31, 53-55.

18. Han, X.M.; Zaldo, C. Sol-gel synthesis of Yb-doped $\mathrm{NaLu}\left(\mathrm{WO}_{4}\right)_{2}$ films. Phys. Procedia 2010, 8 , $18-21$.

19. Xiao, Z.S.; Serna, R.; Afonso, C.N.; Cheng, G.A.; Vickridge, I. Improving the photoluminescence response of Er-Tm: $\mathrm{Al}_{2} \mathrm{O}_{3}$ films by $\mathrm{Yb}$ codoping. J. Lumin. 2007, 122, 32-35.

20. Serna, R.; Suarez-Garcia, A.; de Castro, M.J.; Afonso, C.N. Improving the photoluminescence of thin films by nanostructuring the rare-earth ion distribution. Appl. Surf. Sci. 2005, 247, 8-17.

21. Balestrieri, M.; Ferblantier, G.; Colis, S.; Schmerber, G.; Ulhaq-Bouillet, C.; Muller, D.; Slaoui, A.; Dinia, A. Structural and optical properties of Yb-doped $\mathrm{ZnO}$ films deposited by magnetron reactive sputtering for photon conversion. Sol. Energy Mater. Sol. Cells 2013, 117, 363-371.

22. Soumahoro, I.; Schmerber, G.; Douayar, A.; Colis, S.; Abd-Lefdil, M.; Hassanain, N.; Berrada, A.; Muller, D.; Slaoui, A.; Rinnert, H.; et al. Structural, optical, and electrical properties of Yb-doped $\mathrm{ZnO}$ thin films prepared by spray pyrolysis method. J. Appl. Phys. 2011, 109, doi:10.1063/1.3544307. 
23. Qi, J.H.; Wang, F.X.; Lu, F.; Qin, X.F.; Liu, Z.H.; Yang, G.; Li, L.J.; Chen, Z.H.; Song, H.L. Optical and structural properties of $\mathrm{Yb}$-doped $\mathrm{ZnO}$ thin waveguide films with Er+ ions implantation. In Advanced in Nanoscience and Technology; Cong, H.L., Ed.; Trans Tech Pubications Ltd.: Stafa-Zurich, Switzerland, 2012; Volume 465, pp. 150-154.

24. Garskaite, E.; Flø, A.S.; van Helvoort, A.T.J.; Kareiva, A.; Olsen, E. Investigations of near IR photoluminescence properties in $\mathrm{TiO}_{2}: \mathrm{Nd}, \mathrm{Yb}$ materials using hyperspectral imaging methods. J. Lumin. 2013, 140, 57-64.

25. Forissier, S.; Roussel, H.; Chaudouet, P.; Pereira, A.; Deschanvres, J.L.; Moine, B. Thulium and ytterbium-doped titanium oxide thin films deposited by ultrasonic spray pyrolysis. J. Therm. Spray Technol. 2012, 21, 1263-1268.

26. Dakhel, A.A. Effect of ytterbium doping on the optical and electrical properties of intrinsic $\operatorname{In}_{2} \mathrm{O}_{3}$ thin films. Microelectron. Reliab. 2010, 50, 211-216.

27. Weingartner, R.; Erlenbach, O.; Winnacker, A.; Welte, A.; Brauer, I.; Mendel, H.; Strunk, H.P.; Ribeiro, C.T.M.; Zanatta, A.R. Thermal activation, cathodo- and photoluminescence measurements of rare earth doped (Tm, Tb, Dy, Eu, Sm, Yb) amorphous/nanocrystalline AlN thin films prepared by reactive rf-sputtering. Opt. Mater. 2006, 28, 790-793.

28. Zhao, X.W.; Komuro, S. Time-resolved photoluminescence of ytterbium-doped nanocrystalline Si thin films. Appl. Phys. Lett. 2001, 79, 2151-2153.

29. Ferrand, B.; Chambaz, B.; Couchaud, M. Liquid phase epitaxy: A versatile technique for the development of miniature optical components in single crystal dielectric media. Opt. Mater. 1999, 11, 101-114.

30. Peeva, A.; Dikovska, A.O.; Atanasov, P.A.; de Castroc, M.; Skorupa, W. Rare-earth implanted $\mathrm{Y}_{2} \mathrm{O}_{3}$ thin films. Appl. Surf. Sci. 2007, 253, 8165-8168.

31. Kumar, S.R.S.; Cha, D.K.; Alshareef, H.N. Lattice dynamics and substrate-dependent transport properties of (In, Yb)-doped $\mathrm{CoSb}_{3}$ skutterudite thin films. J. Appl. Phys. 2011, 110, doi:10.1063/1.3651382.

32. Jung, T.; Kim, S.; Song, P. Characteristics of amorphous Yb-doped ITO films deposited on polyimide substrate by DC magnetron sputtering. Surf. Coat. Technol. 2010, 205, S318-S323.

33. Kuzminykh, Y.; Scheife, H.; Bar, S.; Petermann, K.; Huber, G. PLD-grown Yb-doped sesquioxide films on sapphire and quartz substrates. In Proceedings of the COLA'05: 8th International Conference on Laser Ablation, Banff, AB, Canada, 11-16 September 2005; Hess, W.P., Herman, P.R., Bauerle, D., Koinuma, H., Eds.; IOP Publishing Ltd.: Bristol, UK, 2007; Volume 59, pp. 462-465.

34. Tan, M.C.; Patil, S.D.; Riman, R.E. Transparent infrared-emitting $\mathrm{CeF}_{3}$ :Yb-Er polymer nanocomposites for optical applications. ACS Appl. Mater. Interfaces 2010, 2, 1884-1891.

35. Yi, G.-S.; Chow, G.-M. Water-soluble $\mathrm{NaYF}_{4}: \mathrm{Yb}, \operatorname{Er}(\mathrm{Tm}) / \mathrm{NaYF}_{4} /$ polymer core/shell/shell nanoparticles with significant enhancement of upconversion fluorescence. Chem. Mater. 2006, 19, 341-343.

36. Kim, H.; Cha, M.C.; Park, H.W.; Chang, J.Y. Preparation of a Yb(III)-incorporated porous polymer by post-coordination: Enhancement of gas adsorption and catalytic activity. J. Polym. Sci. Part A: Polym. Chem. 2013, 51, 5291-5297. 
37. Prajzler, V.; Hüttel, I.; Špirková, J.; Oswald, J.; Peřina, V.; Machovič, V.; Jeřábek, V. Properties of sputtered carbon layers containing erbium and ytterbium ions. Electron. Devices Syst. EDS 2006 IMAPS CS 2006, 403-408.

38. Patsalas, P. Optical properties of amorphous carbons and their applications and perspectives in photonics. Thin Solid Films 2011, 519, 3990-3996.

39. Robertson, J. Diamond-like amorphous carbon. Mater. Sci. Eng. R 2002, 37, 129-281.

40. Huttel, I.; Gurovic, J.; Cerny, F.; Pospisil, J. Carbon and carbon nitride planar waveguides on silicon substrates. Diam. Relat. Mater. 1999, 8, 628-630.

41. Haas, Y.; Stein, G.; Wurzberg, E. Radiationless transitions in solutions: Isotope and proximity effects on $\mathrm{Dy}^{3+}$ by C-H and C-N bonds. J. Chem. Phys. 1974, 60, 258-263.

42. Artizzu, F.; Quochi, F.; Saba, M.; Loche, D.; Mercuri, M.L.; Serpe, A.; Mura, A.; Bongiovanni, G.; Deplano, P. Silica sol-gel glasses incorporating dual-luminescent Yb quinolinolato complex: Processing, emission and photosensitising properties of the "antenna" ligand. Dalton Trans. 2012, $41,13147-13153$.

43. Boulon, G. Why so deep research on $\mathrm{Yb}^{3+}$-doped optical inorganic materials? J. Alloys Compd. 2008, 451, 1-11.

44. Hsu, H.-L.; Leong, K.R.; Teng, I.-J.; Halamicek, M.; Juang, J.-Y.; Jian, S.-R.; Qian, L.; Kherani, N.P. Erbium-doped amorphous carbon-based thin films: A photonic material prepared by low-temperature RF-PEMOCVD. Materials 2014, 7, 1539-1554.

45. Tsai, R.Y.C.; Qian, L.; Alizadeh, H.; Kherani, N.P. Room-temperature photoluminescence in erbium-doped deuterated amorphous carbon prepared by low-temperature MO-PECVD. Opt. Express 2009, 17, 21098-21107.

46. Lunstroot, K.; Driesen, K.; Nockemann, P.; van Hecke, K.; van Meervelt, L.; Gorller-Walrand, C.; Binnemans, K.; Bellayer, S.; Viau, L.; le Bideau, J.; et al. Lanthanide-doped luminescent ionogels. Dalton Trans. 2009, 14, 298-306.

47. Denoyer, A.; Levesque, Y.; Jandl, S.; Goldner, P.; Guillot-Noel, O.; Viana, B.; Thibault, F.; Pelenc, D. Cooperative emission study in ytterbium-doped $\mathrm{Y}_{2} \mathrm{SiO}_{5}$. J. Lumin. 2008, 128, 1389-1393.

48. Wade, J.L.G. Organic Chemistry; Pearson Education: Upper Saddle River, NJ, USA, 2008.

49. Siebrand, W. Radiationless transitions in polyatomic molecules. I. Calculation of Franck-Condon Factors. J. Chem. Phys. 1967, 46, 440-447.

50. Saleh, B.E.A.; Teich, M.C. Fundamentals of Photonics; Wiley: Hoboken, NJ, USA, 2007.

51. Ogasawara, H.; Kotani, A.; Thole, B.T. Lifetime effect on the multiplet structure of $4 \mathrm{~d}$ X-ray-photoemission spectra in heavy rare-earth elements. Phys. Rev. B 1994, 50, 12332-12341.

52. Padalia, B.D.; Lang, W.C.; Norris, P.R.; Watson, L.M.; Fabian, D.J. X-ray photoelectron core-level studies of the heavy rare-earth metals and their oxides. Proc. R. Soc. Lond. Ser. A Math. Phys. Sci. 1977, 354, 269-290.

53. Signorelli, A.J.; Hayes, R.G. X-ray photoelectron spectroscopy of various core levels of Lanthanide Ions: The roles of monopole excitation and electrostatic coupling. Phys. Rev. B 1973, 8, 81-86.

54. Zanatta, A.R. Effect of thermal annealing treatments on the optical properties of rare-earth-doped AlN films. J. Phys. D: Appl. Phys. 2009, 42, doi:10.1088/0022-3727/42/2/025109. 
55. Tikhomirov, V.K.; Vosch, T.; Fron, E.; Rodriguez, V.D.; Velazquez, J.J.; Kirilenko, D.; van Tendeloo, G.; Hofkens, J.; van der Auweraer, M.; Moshchalkov, V.V. Luminescence of oxyfluoride glasses co-doped with $\mathrm{Ag}$ nanoclusters and $\mathrm{Yb}^{3+}$ ions. RSC Adv. 2012, 2, 1496-1501.

56. Chen, D.; Yu, Y.; Huang, P.; Wang, Y. Nanocrystallization of lanthanide trifluoride in an aluminosilicate glass matrix: Dimorphism and rare earth partition. Cryst. Eng. Comm. 2009, 11, 1686-1690.

57. Wang, X.; Yan, X. Ultraviolet and infrared photon-excited synergistic effect in $\mathrm{Er}^{3+}$-doped $\mathrm{YbF}_{3}$ phosphors. Opt. Lett. 2011, 36, 4353-4355.

58. Ahmed, M.H.; Byrne, J.A.; McLaughlin, J. Evaluation of glycine adsorption on diamond like carbon (DLC) and fluorinated DLC deposited by plasma-enhanced chemical vapour deposition (PECVD). Surf. Coat. Technol. 2012, 209, 8-14.

59. Bendavid, A.; Martin, P.J.; Randeniya, L.; Amin, M.S.; Rohanizadeh, R. The properties of fluorine-containing diamond-like carbon films prepared by pulsed DC plasma-activated chemical vapour deposition. Diam. Relat. Mater. 2010, 19, 1466-1471.

60. Ahmed, S.F.; Banerjee, D.; Chattopadhyay, K.K. The influence of fluorine doping on the optical properties of diamond-like carbon thin films. Vacuиm 2010, 84, 837-842.

61. Foong, Y.M.; Hsieh, J.; Li, X.; Chua, D.H.C. The study on the effect of erbium on diamond-like carbon deposited by pulsed laser deposition technique. J. Appl. Phys. 2009, 106, doi:10.1063/1.3211986.

62. Foong, Y.M.; Hsieh, J.; Li, X.; Chua, D.H.C. Comparative study between erbium and erbium oxide-doped diamondlike carbon films deposited by pulsed laser deposition technique. J. Vac. Sci. Technol. A 2010, 28, 449-455.

63. Iakovlev, S.; Solterbeck, C.H.; Es-Souni, M.; Zaporojtchenko, V. Rare-earth ions doping effects on the optical properties of sol-gel fabricated $\mathrm{PbTiO}_{3}$ thin films. Thin Solid Films 2004, 446, 50-53.

64. Hsu, H.-L.; Leong, K.R.; Halamicek, M.; Teng, I.J.; Mahtani, P.; Juang, J.-Y.; Jian, S.-R.; Qian, L.; Kherani, N.P. In-situ doping of erbium in hydrogenated amorphous carbon by low temperature metalorganic radio frequency plasma enhanced chemical vapor deposition. Thin Solid Films 2014, in press.

65. Hoang, J.; Schwartz, R.N.; Wang, K.L.; Chang, J.P. The effects of energy transfer on the $\mathrm{Er}^{3+}$ $1.54 \mu \mathrm{m}$ luminescence in nanostructured $\mathrm{Y}_{2} \mathrm{O}_{3}$ thin films with heterogeneously distributed $\mathrm{Yb}^{3+}$ and $\mathrm{Er}^{3+}$ codopants. J. Appl. Phys. 2012, 112, doi:10.1063/1.4752754.

66. Forouhi, A.R.; Bloomer, I. Optical dispersion-relations for amorphous-semiconductors and amorphous dielectrics. Phys. Rev. B 1986, 34, 7018-7026.

(C) 2014 by the authors; licensee MDPI, Basel, Switzerland. This article is an open access article distributed under the terms and conditions of the Creative Commons Attribution license (http://creativecommons.org/licenses/by/3.0/). 